Atmos. Chem. Phys., 14, 4029-4054, 2014

www.atmos-chem-phys.net/14/4029/2014/

doi:10.5194/acp-14-4029-2014

(c) Author(s) 2014. CC Attribution 3.0 License.

\title{
Deuterium excess as a proxy for continental moisture recycling and plant transpiration
}

\author{
F. Aemisegger ${ }^{1}$, S. Pfahl ${ }^{1}$, H. Sodemann ${ }^{1}$, I. Lehner ${ }^{1,2}$, S. I. Seneviratne ${ }^{1}$, and H. Wernli ${ }^{1}$ \\ ${ }^{1}$ Institute for Atmospheric and Climate Science, ETH Zurich, Zurich, Switzerland \\ ${ }^{2}$ Centre for Environmental and Climate Research, Lund University, Lund, Sweden \\ Correspondence to: F. Aemisegger (franziska.aemisegger@usys.ethz.ch)
}

Received: 17 September 2013 - Published in Atmos. Chem. Phys. Discuss.: 13 November 2013

Revised: 20 February 2014 - Accepted: 17 March 2014 - Published: 23 April 2014

\begin{abstract}
Studying the evaporation process and its link to the atmospheric circulation is central for a better understanding of the feedbacks between the surface water components and the atmosphere. In this study, we use 5 months of deuterium excess $(d)$ measurements at the hourly to daily timescale from a cavity ring-down laser spectrometer to characterise the evaporation source of low-level continental water vapour at the long-term hydrometeorological monitoring site Rietholzbach in northeastern Switzerland. To reconstruct the phase change history of the air masses in which we measure the $d$ signature and to diagnose its area of surface evaporation we apply a Lagrangian moisture source diagnostic. With the help of a correlation analysis we investigate the strength of the relation between $d$ measurements and the moisture source conditions. Temporal episodes with a duration of a few days of strong anticorrelation between $d$ and relative humidity as well as temperature are identified. The role of plant transpiration, the large-scale advection of remotely evaporated moisture, the local boundary layer dynamics at the measurement site and recent precipitation at the site of evaporation are discussed as reasons for the existence of these modes of strong anticorrelation between $d$ and moisture source conditions. We show that the importance of continental moisture recycling and the contribution of plant transpiration to the continental evaporation flux may be deduced from the $d$-relative humidity relation at the seasonal timescale as well as for individual events. The methodology and uncertainties associated with these estimates of the transpiration fraction of evapotranspiration are presented and the proposed novel framework is applied to individual events from our data set. Over the whole analysis period (August to December 2011) a transpiration fraction of the evapotranspiration flux over the continental part of the moisture source
\end{abstract}

region of $62 \%$ is found albeit with a large event-to-event variability ( $0 \%$ to $89 \%)$ for continental Europe. During days of strong local moisture recycling a higher overall transpiration fraction of $76 \%$ (varying between $65 \%$ and $86 \%$ ) is found. These estimates are affected by uncertainties in the assumptions involved in our method as well as by parameter uncertainties. An average uncertainty of $11 \%$ results from the strong dependency of the transpiration estimates on the choice of the non-equilibrium fractionation factor. Other uncertainty sources like the influence of boundary layer dynamics are probably large but more difficult to quantify. Nevertheless, such Lagrangian estimates of the transpiration part of continental evaporation could potentially be useful for the verification of model estimates of this important landatmosphere coupling parameter.

\section{Introduction}

Evaporation of water from the earth surface is a key coupling process in the hydrological cycle between the earth surface and the atmosphere. The energy available from global radiation for the phase change from liquid water in the land surface reservoirs to water vapour in the atmosphere is modulated by meteorological conditions. On continental surfaces, the actual moisture flux from the land to the atmosphere is further constrained by the available soil water and groundwater (e.g. Entekhabi and Eagleson, 1989; Koster et al., 2004; Seneviratne et al., 2010). The evapotranspiration flux in turn feeds back on the temperature and humidity conditions of the lower atmosphere (e.g. Betts, 2004; Seneviratne et al., 2006; Mueller and Seneviratne, 2012). Long-term changes in spatial and seasonal evaporation patterns over land and 
ocean were identified in model simulations and observationbased data sets for the twentieth century (e.g. Bosilovich et al., 2005; Jung et al., 2010; Douville et al., 2013) and for future climate projections (Held and Soden, 2006; Seneviratne et al., 2006; Boé and Terray, 2008). Positive trends in ocean evaporation in the last decade were diagnosed from satellite observations (Schlosser and Houser, 2007; Yu and Weller, 2007). Such changes in surface evaporation driven by changes in atmospheric conditions have a strong impact on the regional continental water cycle and the strength of the coupling between the earth surface and the atmosphere (Seneviratne et al., 2010). Studying the evaporation process and its link to the atmospheric circulation is thus central for a better understanding of the feedbacks between the earth surface and the atmosphere.

To investigate the impact of atmospheric circulation on surface evaporation and the subsequent transport of moisture in the atmosphere, the use of stable water isotopologues $\left({ }^{1} \mathrm{H}_{2}{ }^{16} \mathrm{O},{ }^{2} \mathrm{H}^{1} \mathrm{H}^{16} \mathrm{O}\right.$ and $\left.{ }^{1} \mathrm{H}_{2}{ }^{18} \mathrm{O}\right)$ as a proxy in combination with Lagrangian modelling techniques is an established approach (see e.g. Gat et al., 2003; Pfahl and Wernli, 2008; Sodemann et al., 2008b). In a Lagrangian framework the history of air parcels can be followed back in time using global or regional (re-)analysis data of the three-dimensional atmospheric wind fields. Such a modelling approach is appropriate to relate the geographical location of the measurement of stable water isotopes in atmospheric water vapour with the location of surface evaporation of this moisture. The moisture source can be local (i.e., close to the measurement site), remote (e.g. $>100 \mathrm{~km}$ away from the site), or a combination of the two. The dependency of the isotope fractionation processes during phase changes on environmental variables like temperature, relative humidity and wind speed makes stable water isotopes particularly suited for the study of the complex atmospheric controls on evaporation.

The isotopic content of a water vapour sample is expressed in terms of the relative deviation of the isotopic mixing ratio from an internationally accepted standard $\left(\delta=\frac{R_{\text {sample }}-R_{\text {standard }}}{R_{\text {standard }}}\right)$ and is indicated in permil $(\% o)$. When thermodynamic equilibrium prevails (i.e., for saturated conditions), the variability of $\delta^{2} \mathrm{H}$ in natural waters is approximately 8 times larger than the variability in $\delta^{18} \mathrm{O}$. This is due to the differences in the saturation vapour pressure of the two heavy isotopologues ${ }^{2} \mathrm{H}^{1} \mathrm{H}^{16} \mathrm{O}$ and ${ }^{1} \mathrm{H}_{2}{ }^{18} \mathrm{O}$. Equilibrium fractionation is theoretically well understood (Bigleisen, 1961) and has been studied in laboratory experiments (e.g. Horita and Wesolowski, 1994). The temperaturedependent equilibrium fractionation factor $\alpha=\frac{R_{1}}{R_{\mathrm{v}}}$, relates the isotope ratio of the condensate $R_{1}$ to the isotope ratio of the vapour phase $R_{\mathrm{v}}$. Non-equilibrium fractionation occurring in unsaturated conditions, results from differences in the diffusivity of the different isotopes. To quantify the deviation from thermodynamic equilibrium during phase changes, the second-order isotope parameter deuterium excess $d$ has often been used (e.g. Dansgaard, 1964; Merlivat and Jouzel, 1979; Gat, 1996; Pfahl and Wernli, 2008; Welp et al., 2012):

$d=\delta^{2} \mathrm{H}-8 \cdot \delta^{18} \mathrm{O}$.

Because equilibrium fractionation is temperature dependent, the ratio of the two equilibrium fractionation factors $s(T)=$ $\frac{\alpha_{2} \mathrm{H}}{\alpha_{18}-1}$ varies between 8.6 at $0{ }^{\circ} \mathrm{C}$ and 7.7 at $30^{\circ} \mathrm{C}$ (Majoube, 1971). $d$ can thus slightly change even under thermodynamic equilibrium conditions. Since non-equilibrium fractionation is intrinsically dominant during evaporation, $d$ is an interesting variable for the study of surface evaporation and the associated meteorological conditions. Craig (1961) found that the global mean meteoric water has a $d$ of $10 \%$, reflecting the fact that the ocean is generally out of equilibrium with the atmosphere and the mean relative humidity of air at the evaporating ocean surface is $<100 \%$.

In the following we present a short review on the use of $d$ as a proxy for ocean evaporation (Sect. 1.1). In Sect. 1.2 we summarise the findings from studies aimed at understanding which processes control $d$ in low-level continental moisture, which is generally also affected by land surface evaporation processes like soil evaporation and plant transpiration.

\section{1 $d$ as a proxy for ocean evaporation}

Merlivat and Jouzel (1979) published one of the first studies using the $d$ signal in precipitation to derive global mean sea surface temperatures and relative humidity above the ocean. The relationship presented by Merlivat and Jouzel (1979) involves the so-called closure assumption of a climate in steady state, in which ocean evaporation is the only source of moisture for the atmospheric boundary layer. Using the Craig and Gordon (1965) linear resistance model for evaporation and applying the closure assumption discussed in Merlivat and Jouzel (1979), the following relationship can be obtained between $d$ of the ocean evaporation flux, sea surface temperature (SST) in ${ }^{\circ} \mathrm{C}$ and relative humidity with respect to sea surface temperature $h_{\mathrm{s}}$ (s stands for surface) in \% (see coloured solid lines in Fig. 1):

$d=0.33 \cdot \mathrm{SST}-0.44 \cdot h_{\mathrm{s}}+37$.

The $d$ in the evaporation flux increases with decreasing $h_{\mathrm{s}}$ and increasing SST in accordance with the general physical understanding of equilibrium and non-equilibrium fractionation.

The theoretical link between $d$ in atmospheric moisture and $h_{\mathrm{S}}$ as well as SST at the location of evaporation thus provides a powerful framework to study remote evaporation conditions using $d$ as a proxy. Many early model studies used the Craig and Gordon (1965) model together with the closure assumption to relate initial isotope concentrations in the air parcel to conditions at the evaporative source (e.g. Jouzel and Merlivat, 1984; Johnsen et al., 1989; Petit et al., 1991). 


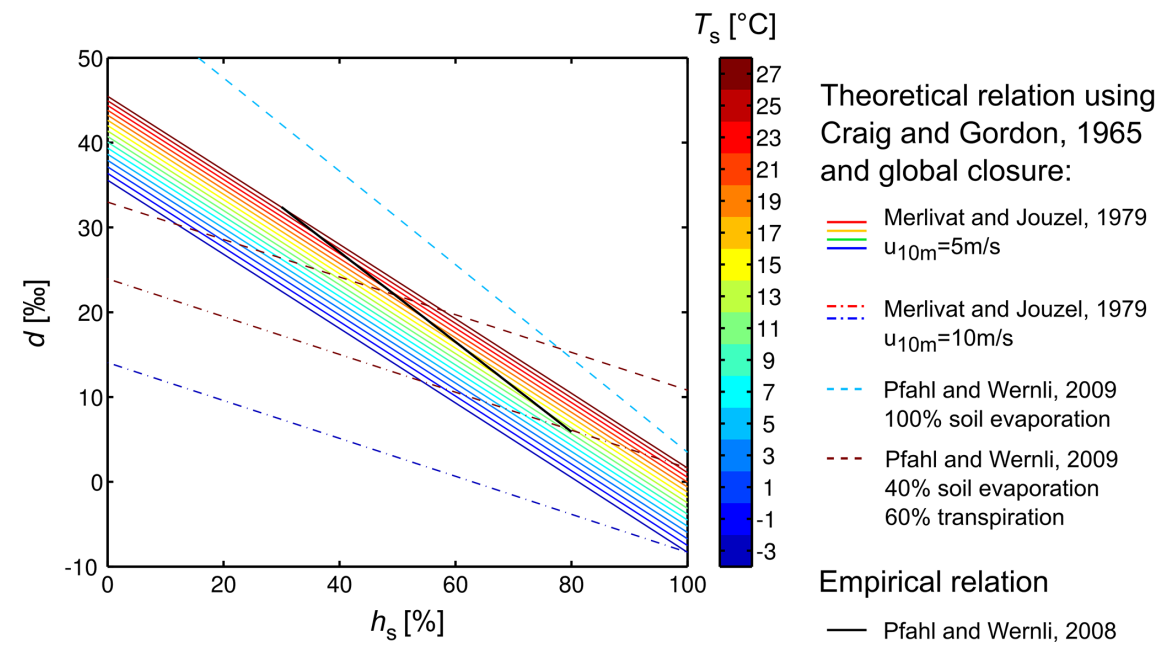

Fig. 1. The $d$ in the evaporation flux as parameterised by the Craig-Gordon linear resistance model (Craig and Gordon, 1965) using the closure assumption from Merlivat and Jouzel (1979). Different non-equilibrium fractionation factors were used for the different lines. For the solid coloured lines the non-equilibrium fractionation factors of Merlivat and Jouzel (1979) were used with $u_{10 \mathrm{~m}}=5 \mathrm{~ms} \mathrm{~s}^{-1}$. For the red and the blue dash-dotted line the non-equilibrium fractionation factors of Merlivat and Jouzel (1979) were used with $10 \mathrm{~m}$ wind speeds of $u_{10 \mathrm{~m}}=10 \mathrm{~m} \mathrm{~s}^{-1}$. The black line shows the empirical relationship of Pfahl and Wernli (2008). The dashed red line represents the evaporation flux $d$ from the land surface in summer assuming $40 \%$ fractionating bare soil evaporation with non-equilibrium factors of $\alpha^{\mathrm{k}}=1.0039$ for $\delta^{2} \mathrm{H}$ and $\alpha^{\mathrm{k}}=1.0076$ for $\delta^{18} \mathrm{O}$ (Pfahl and Wernli, 2009) and $60 \%$ non fractionating transpiration (e.g. Yepez et al., 2005; Lawrence et al., 2007; Sutanto et al., 2012). The soil moisture isotopic composition for the red dashed line was chosen to be $\delta^{2} \mathrm{H}=-88 \%$ o, $\delta^{18} \mathrm{O}=-12 \%$, which results in a source vapour $d_{\mathrm{s}}^{\mathrm{r}}$ at $h=100 \%$ and $27^{\circ} \mathrm{C}$ of $d_{\mathrm{s}}^{\mathrm{r}}=10.8 \%$. The dashed blue line represents $d$ of the evaporation flux from the land surface in winter assuming $100 \%$ bare soil evaporation with non-equilibrium factors of $\alpha^{\mathrm{k}}=1.0039$ for $\delta^{2} \mathrm{H}$ and $\alpha^{\mathrm{k}}=1.0076$ for $\delta^{18} \mathrm{O}$ (Pfahl and Wernli, 2009). The soil moisture isotopic composition for the blue dashed line was chosen to be $\delta^{2} \mathrm{H}=-200 \%$ o, $\delta^{18} \mathrm{O}=-24 \%$, which results in a source moisture $d_{\mathrm{s}}^{\mathrm{r}}=3.5 \%$ o for $T_{\mathrm{S}}=5{ }^{\circ} \mathrm{C}$. The estimates for the soil moisture isotopic composition are best guesses of typical values for winter and summer.

These studies showed that the $d$ signature of the evaporation conditions is at least partially conserved along the trajectory of the advected vapour until rainout, for example, over the Greenland ice sheet. General circulation models (GCMs) equipped with stable water isotope physics (e.g. Joussaume et al., 1984; Hoffmann et al., 1998) explicitly simulated evaporation using the Craig and Gordon (1965) model. These models generally reproduced the climatological signals of the individual isotopes in precipitation reasonably well. The $d$ signal as simulated by GCMs, however, suffers from large biases (Jouzel et al., 2007; Yoshimura et al., 2008; Risi et al., 2010, 2013b).

Jouzel and Koster (1996) showed that GCM-derived $d$ in the evaporation flux over the ocean was strongly correlated with $h_{\mathrm{S}}$ and SST, when using the approach of Craig and Gordon (1965) without the closure assumption. For this case they deduced the relationship $d=0.38 \cdot \mathrm{SST}-0.238 \cdot h_{\mathrm{s}}+23.1$. When assuming closure to compute the initial isotopic composition of water vapour over the ocean using the SST, $h_{\mathrm{S}}$ and $\delta_{\text {ocean }}$ data from the GCM, Jouzel and Koster (1996) found a slightly different relationship: $d=0.598 \cdot \mathrm{SST}-0.381 \cdot h_{\mathrm{s}}+$ 25.5. The feedback of the atmospheric moisture on the isotopic composition of the evaporation flux seems to weaken the sensitivity of $d$ to changes in SST and $h_{\mathrm{s}}$ in the GCM used by Jouzel and Koster (1996). The closure assumption thus may lead to an overestimation of the slope of the $d-h_{\mathrm{s}}$ relationship.

In several recent studies, $d$ samples obtained from the oceanic boundary layer (Gat et al., 2003; Uemura et al., 2008) or from a near-ocean site over land (Pfahl and Wernli, 2008) were shown to be a good proxy for the meteorological conditions over the ocean at the point of evaporation. Pfahl and Wernli (2008) showed that for isotope data measured in Rehovot (Israel) between 1998 and 2006 on short timescales ( $8 \mathrm{~h}$ accumulation time on average) $d$ was primarily a proxy for $h_{\mathrm{S}}$ at the point of evaporation of the probed moisture and not for SST (see black line in Fig. 1). Uemura et al. (2008) performed ship measurements over the Southern Ocean and found a linear multivariate relationship between $d, h_{\mathrm{s}}$ and SST. The slope of the linear dependency between $d$ and $h_{\mathrm{s}}$, which is a central measure used in our study, is very similar in Uemura et al. (2008) and Pfahl and Wernli (2008) with $-0.52 \% \circ \%^{-1}$ and $-0.53 \% \%^{-1}$ respectively. Both studies analysed isotope data from moisture that directly emanates from ocean evaporation without any relevant influence of continental moisture recycling processes. On a climatological timescale $d$ is mainly used as a proxy for SST (Johnsen et al., 1989; Vimeux et al., 1999) based on the argument that GCM simulations show only small glacial-tointerglacial changes in $h_{\mathrm{s}}$. 
In the present study, we investigate the isotopic composition of low-level continental moisture, which generally only partly originates from ocean evaporation and is strongly affected by continental evaporation processes. Thus in the following section the possible influence of continental evaporation on water vapour $d$ and particularly on the linear $d-h_{\mathrm{s}}$ relationship is discussed.

\subsection{The $d$ in continental low-level moisture}

Water isotopes have been used as tools to investigate continental moisture recycling in different studies in the past (e.g. Salati et al., 1979; Gat and Matsui, 1991; Risi et al., 2013). There are some indications from recent vapour measurements at different continental locations in China and North America that the $d$ of continental surface air can be significantly altered by local processes on the subdiurnal timescale (Welp et al., 2012). These authors therefore cast some doubts on whether continental water vapour $d$ can be used as a conserved tracer of environmental conditions during evaporation at the moisture source location. Several processes affect the isotopic composition of water vapour after its evaporation from land or ocean, during its transport. Cloud and precipitation formation, partial below-cloud evaporation of rain droplets, snow formation and mixing with water vapour from other evaporative sources can affect the isotopic composition of the water vapour transported in an air parcel (Ciais and Jouzel, 1994; Field et al., 2010). To a first order, the microphysical processes in clouds can be assumed to occur in conditions of equilibrium between the different phases. Thus, these processes do not strongly affect $d$. Furthermore, it is unclear whether a consistent $d-h_{\mathrm{s}}$ relation as discussed above for ocean evaporation exists for evapotranspiration which is characterised by additional controls like soil moisture and vegetation activity.

The relationship between $d$ and $h_{\mathrm{s}}$ strongly depends on the isotopic composition of the soil moisture and the contribution of transpiration, which can be assumed in first order to be non-fractionating over timescales of $>1$ day (Harwood et al., 1999; Farquhar et al., 2007). The partitioning of the latent heat flux between transpiration and evaporation is a central parameter for its isotopic signature. Isotopes have been used in several studies as a tool for the separation of the land surface latent heat flux into evaporation and transpiration (e.g. Moreira et al., 1997; Yakir and Sternberg, 2000; Yepez et al., 2005; Robertson and Gazis, 2006; Sutanto et al., 2012; Jasechko et al., 2013). The potential influence of land surface processes on the isotopic composition of the evaporation flux is shown in Fig. 1 by the dashed lines. The slope of the $d-$ $h_{\mathrm{s}}$ relation is expected to be smaller when transpiration plays a dominant role in the evapotranspiration flux from the land surface. Welp et al. (2012) indeed found smaller $d-h_{\mathrm{s}}$ slopes for isotope measurements in the continental boundary layer and local $h_{\mathrm{s}}$ measurements $\left(-0.36 \% \%^{-1}\right.$ in New Haven, USA and $-0.22 \% \%^{-1}$ in Borden, Canada) than the ones mentioned above by Jouzel and Koster (1996), Pfahl and Wernli (2008) and Uemura et al. (2008) $\left(\sim-0.5 \% \circ \%{ }^{-1}\right)$.

The ratio of diffusive to turbulent transport in evaporative transition layers as well as the diffusivity of the heavy water molecules in vapour represent further uncertainties in the estimation of the isotopic composition of the evapotranspiration flux as well as for the ocean evaporation flux. As shown in Table 1 the spread of the non-equilibrium fractionation factors for bare soil and ocean evaporation found in the literature is large. Generally, a wind speed dependent description of the non-equilibrium fractionation process is used for ocean evaporation (Merlivat, 1978; Cappa et al., 2003). For high wind speeds the water vapour transport is the same for all the isotopes. For small wind speeds, molecular diffusivity has a more pronounced impact on water vapour transport, which leads to non-equilibrium isotopic fractionation. For continental evaporation, small-scale turbulence may even enhance rather than suppress non-equilibrium fractionation (Lee et al., 2009). Based on their Lagrangian analysis of isotope measurements in Israel, Pfahl and Wernli (2009) suggested a wind speed independent formulation of the non-equilibrium fractionation factor for wind speeds below $15 \mathrm{~m} \mathrm{~s}^{-1}$. For soil evaporation from wet soils, the moisture transfer is controlled by the atmospheric conditions and the same non-equilibrium factors as for an open water surface can be applied (Mathieu and Bariac, 1996). For dry soils, the transfer is dominated by soil characteristics and the transport of water vapour is primarily controlled by molecular diffusivity in the soil. From cryogenically collected soil vapour data Braud et al. (2009a) find that the non-equilibrium fractionation factor is not constant in time and seems to depend on the shape of the vertical soil water isotopic profile.

In this paper we present a Lagrangian analysis of laserbased $d$ measurements (Aemisegger et al., 2012) in continental boundary layer water vapour in northeastern Switzerland at the hydrometeorological measurement station $\mathrm{Ri}$ etholzbach (Seneviratne et al., 2012). Five months of hourly $d$ averages of $5 \mathrm{~s}$ measurements are analysed and interpreted using the corresponding diagnosed remote moisture source $h_{\mathrm{s}}^{\mathrm{r}}$ and skin temperature $\left(T_{\mathrm{s}}^{\mathrm{r}}\right)$ as well as measured local $h_{\mathrm{s}}^{\ell}$ and $T_{\mathrm{s}}^{\ell}$ (see Table 2 for a summary of the variable names). The goal of this study is to tackle the question whether the isotopic composition of continental boundary layer moisture can be considered as a tracer for the evaporation conditions $h_{\mathrm{s}}^{\mathrm{r}}$ and $T_{\mathrm{s}}^{\mathrm{r}}$.

More specifically, the three main aspects addressed are(1) the impact of the boundary layer dynamics on the timescale of low-level moisture memory of evaporation conditions; (2) the influence of land surface processes like recycling and evapotranspiration on the $d-h_{\mathrm{s}}^{\mathrm{r}}$ and the $d-h_{\mathrm{s}}^{\ell}$ relations of continental boundary layer water vapour and (3) the use of the $d-h_{\mathrm{s}}$ relation for estimating the partitioning of continental evapotranspiration in soil evaporation and plant transpiration.

In the following we present the measurement site as well as the measurement techniques used in this study (Sect. 2), 
Table 1. Comparison of kinetic fractionation factors $\alpha^{\mathrm{k}}$ found in the literature, for $10 \mathrm{~m}$ wind velocities between $u_{10 \mathrm{~m}}=0 \mathrm{~s}$ and $u_{10 \mathrm{~m}}=$ $12 \mathrm{~m} \mathrm{~s}^{-1}$ (values show the minimum to maximum value in this range of wind velocities).

\begin{tabular}{lllcc}
\hline Study & Study & Body & \multicolumn{2}{c}{$\left(\alpha^{\mathrm{k}}-1\right) \cdot 1000[\% \mathrm{o}]$} \\
& & & $\delta^{2} \mathrm{H}$ & $\delta^{18} \mathrm{O}$ \\
\hline Merlivat and Jouzel (1979) & lab & open water & $3.08-6.82$ & $2.70-6.01$ \\
Cappa et al. (2003) & lab & open water & $1.73-3.90$ & $3.47-7.65$ \\
Pfahl and Wernli (2009) & field & open water & 3.92 & 7.56 \\
Mathieu and Bariac (1996) & model & bare soil & 16.76 (wet), 25.12 (dry) & 18.72 (wet), 28.07 (dry) \\
\hline
\end{tabular}

Table 2. Description of variable names used in the text.

\begin{tabular}{ll}
\hline Variable name & Description \\
\hline$h_{\mathrm{S}}$ & relative humidity with respect to skin temperature \\
$h_{\mathrm{s}}^{\mathrm{r}}$ & remote $h_{\mathrm{s}}$ diagnosed using the Lagrangian moisture source diagnostics \\
$h_{\mathrm{s}}^{\ell}$ & local $h_{\mathrm{s}}$ measured at Rietholzbach \\
$h_{2 \mathrm{~m}}^{\ell}$ & $h$ with respect to $2 \mathrm{~m}$ temperature measured at Rietholzbach \\
$T_{\mathrm{S}}^{\mathrm{r}}$ & skin temperature \\
$T_{\mathrm{s}}^{\mathrm{r}}$ & remote skin temperature diagnosed \\
& using the Lagrangian moisture source diagnostics \\
$T_{\mathrm{s}}^{\ell}$ & local skin temperature measured at Rietholzbach \\
$T_{2 \mathrm{~m}}^{\ell}$ & local $2 \mathrm{~m}$ air temperature measured at Rietholzbach \\
$d^{\mathrm{r}}$ & deuterium excess measured at Rietholzbach \\
$d_{\mathrm{s}}^{\mathrm{r}}$ & diagnosed deuterium excess of the remote moisture source \\
$d_{\mathrm{s}}^{\ell}$ & diagnosed deuterium excess of the local moisture source \\
$d_{\mathrm{O}}$ & deuterium excess of ocean water \\
$d_{\mathrm{c}}$ & deuterium excess of continental surface water (soil moisture) \\
$d_{\mathrm{p}}$ & deuterium excess of precipitation \\
\hline
\end{tabular}

then we briefly introduce the applied moisture source identification method in Sect. 3 and discuss the moisture sources of water vapour at the Rietholzbach site between August and December 2011 identified with our Lagrangian approach in Sect. 4. The timescale and modes of anticorrelation between $h_{\mathrm{s}}$ and $d$ is discussed in Sect. 5. The occurrence and characteristics of events of high anticorrelation between local $h_{\mathrm{s}}^{\ell}$ or remote $h_{\mathrm{s}}^{\mathrm{r}}$ and $d$ is analysed in Sect. 6. From the analyses of these events we deduce and present a method for quantifying the transpiration fraction of the continental evaporation flux using deuterium excess measurements and the Lagrangian moisture source diagnostics (Sect. 7).

\section{Measurements from the site Rietholzbach}

The isotopes and hydrometeorological measurements used in this study were performed at the Rietholzbach site, situated in the northeastern Swiss Prealps (Seneviratne et al., 2012). The water vapour isotope measurement system was set up during 5 consecutive months (1 August 2011 to 31 December 2011) for hourly measurements at the Rietholzbach site in a lysimeter cellar. The instrument used is a Picarro L1115-i cavity ring-down laser spectrometer. For hourly measurements, the precision of the measurement system for $d$ is $0.3 \%$ and the accuracy is 3.1\%o (see Aemisegger et al., 2012, for technical details). The inlet on the measurement field is at $\sim 1.5 \mathrm{~m}$ height and consists of a rain protection and a $5 \mathrm{~mm}$ stainless steel filter (Fig. 2a). A heated PTFE tubing at $70^{\circ} \mathrm{C}(6 \mathrm{~m}$ long with an inner diameter of $10 \mathrm{~mm}$ ) leads to the instrument in the cellar. Figure $2 \mathrm{c}$ shows a schematic of the flow of ambient air through the measurement system. The main $6 \mathrm{~m}$ tubing is flushed by a membrane pump with a throughflow of $9 \mathrm{~L} \mathrm{~min}^{-1}$. The internal pump of the laser instrument induces a flow of $25 \mathrm{~mL} \mathrm{~min}^{-1}$ through the instrument. The typical travel time of a water molecule from the inlet to the outflow of the measurement system is $\sim 1 \mathrm{~min}$.

Calibration was done two times a day with each time two standards at 03:00 UTC and 15:00 UTC. During the night calibration period, four calibration runs with two standards and two different water vapour mixing ratios were performed. The water vapour mixing ratios were chosen at 3000 ppmv above and 3000 ppmv below the ambient water vapour mixing ratio of the previous $15 \mathrm{~min}$ of ambient air measurements. During the daytime calibration period only two calibration runs were performed at the ambient water vapour mixing ratio with the two standards. If variations in water vapour mixing ratios during the day were $>1000 \mathrm{ppmv}$, 
Table 3. Isotopic composition of the standards used for calibration of the laser water vapour isotope measurements for 1 August 2011 to 18 November 2011 (period 1) and 18 November 2011 to 31 December 2011 (period 2).

\begin{tabular}{|c|c|c|c|c|}
\hline & \multicolumn{2}{|c|}{ Standard 1} & \multicolumn{2}{|c|}{ Standard 2} \\
\hline & period 1 & period 2 & period 1 & period 2 \\
\hline$\delta^{2} \mathrm{H}$ & $-78.68 \% o$ & $-78.68 \%$ & $-153.90 \%$ & $-256.11 \%$ \\
\hline$\delta^{18} \mathrm{O}$ & $-10.99 \%$ & $-10.99 \%$ & $-24.89 \%$ & $-46.02 \%$ \\
\hline
\end{tabular}

the measurements were corrected for water vapour mixing ratio dependency (see Aemisegger et al., 2012). The water vapour mixing ratio corrected $\delta^{18} \mathrm{O}$ and $\delta^{2} \mathrm{H}$ measurements were then normalised to the international VSMOW2VSLAP2 scale (IAEA, 2009) using the known reference standards with a linear relation between the measured standard $\delta$ values and their reference value (Table 3 ). The $d=$ $\delta^{2} \mathrm{H}-8 \cdot \delta^{18} \mathrm{O}$ was obtained from the calibrated $\delta$ measurements. The $5 \mathrm{~s}$ calibrated water vapour measurements were averaged to hourly isotope and water vapour mixing ratio data.

Bi-weekly accumulated water samples from the lysimeter

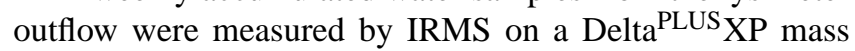
spectrometer (Thermo Fisher Scientific Inc., Germany) for the whole measurement period.

\section{Lagrangian moisture source diagnostic}

An established moisture source diagnostic (Sodemann et al., 2008a) is used in this paper to identify the $h_{\mathrm{s}}^{\mathrm{r}}$ and $T_{\mathrm{s}}^{\mathrm{r}}$ conditions at the evaporative sources of atmospheric water vapour analysed for its isotopic composition at the Rietholzbach site. This Lagrangian tool is based on the diagnosis of changes in specific humidity along backward trajectories started at the location of measurement. Lagrangian techniques have been used in previous studies for the interpretation of stable water isotope measurements especially in precipitation (Rindsberger et al., 1983; Anker et al., 2007; Barras and Simmonds, 2008; Sodemann et al., 2008b) but also in water vapour (Gat et al., 2003; Lawrence et al., 2004; Strong et al., 2007; Pfahl and Wernli, 2008).

The first step in the identification procedure of moisture sources is the trajectory calculation as described in Sect. 3.1. Then the moisture source diagnostic tool to identify the moisture sources (uptake points) and the meteorological conditions at the source locations is applied as presented in Sect. 3.2.

\subsection{Trajectory calculations}

Two different model data sets have been used in this paper to compute kinematic three-dimensional backward trajectories using the method of Wernli and Davies (1997). On the global scale we used 6-hourly data from the ERA-Interim reanalyses (Dee et al., 2011) interpolated on a horizontal grid with a grid spacing of $1^{\circ}$. On the regional scale we used hourly analysis data of the limited-area model COSMO (Doms and Schättler, 2002; Steppeler et al., 2003) provided operationally by MeteoSwiss with $7 \mathrm{~km}$ horizontal grid spacing.

The measurement site Rietholzbach is situated in northeastern Switzerland $\left(47.38^{\circ} \mathrm{N}, 8.99^{\circ} \mathrm{E}\right)$ at an elevation of 755 ma.s.l. (Seneviratne et al., 2012). Five horizontal starting points were selected for the trajectories in a cross arrangement with the location of the isotope measurement station Rietholzbach in the centre of the cross. The four points defining the cross edges were shifted by $0.2^{\circ}$ in the meridional and zonal direction from the measurement site, respectively.

A constant maximum starting height of 1800 ma.s.l. was set to cover a representative part of the lower troposphere, where the water vapour isotope measurements were conducted. Seven vertical levels were thus selected as starting points for the COSMO trajectories, corresponding to every second model level between levels 1 and 13 (between 780 ma.s.1. and 1800 ma.s.1. every $\sim 150 \mathrm{~m}$ ). With this setting, in total 35 trajectories were computed five days backward in time for every hour in the period August to December 2011 using COSMO analysis fields. With the ERA-Interim analysis data every second model level was chosen between levels 1 and 11 (between 780 ma.s.l. and 1800 ma.s.l. every $\sim 200 \mathrm{~m}$ ) leading to 25 trajectories that were computed ten days backwards in time every six hours for the same time period. Several meteorological variables including specific humidity, $2 \mathrm{~m}$ temperature, $2 \mathrm{~m}$ dew point temperature, skin temperature, and boundary layer height, were interpolated along the backward trajectories from both models for the Lagrangian diagnostic and further analysis. In general, ERA-Interim surface conditions and observational data sets have been shown to be in good agreement (Simmons, et al., 2010; Pfahl and Niedermann, 2011).

\subsection{Moisture source diagnostic}

The Lagrangian moisture source analysis used in this study was developed by Sodemann et al. (2008a) for identifying moisture sources of precipitation. The same diagnostic tool was applied in Pfahl and Wernli (2008) for the interpretation of water vapour isotope data. With this technique, evaporation sites of the moisture can be identified by following the air parcels back in time and registering changes in specific humidity along the trajectories. Positive increments in specific humidity along trajectories for a given time increment ( $1 \mathrm{~h}$ for COSMO and $6 \mathrm{~h}$ for ERA-Interim) are regarded as moisture uptakes from the underlying surface at the centre of the corresponding trajectory segment. Each uptake location is weighted according to its contribution to the final humidity of the trajectory. If a decrease in specific humidity (i.e., precipitation) occurs along a trajectory after one or more 
a) Inlet

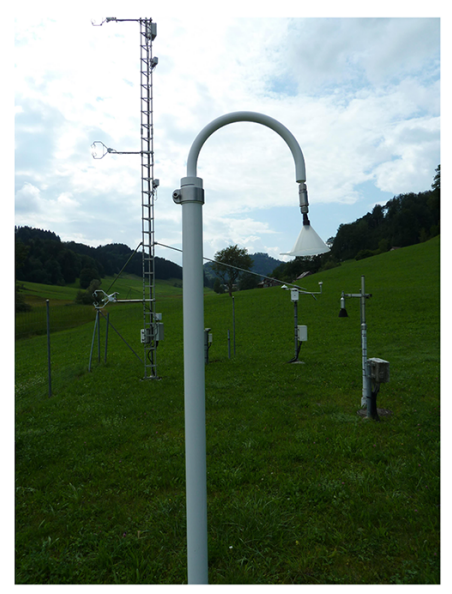

b) Laser system in the lysimeter cellar

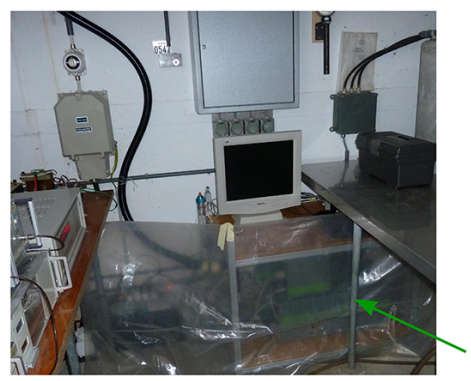

c) Flow diagramm

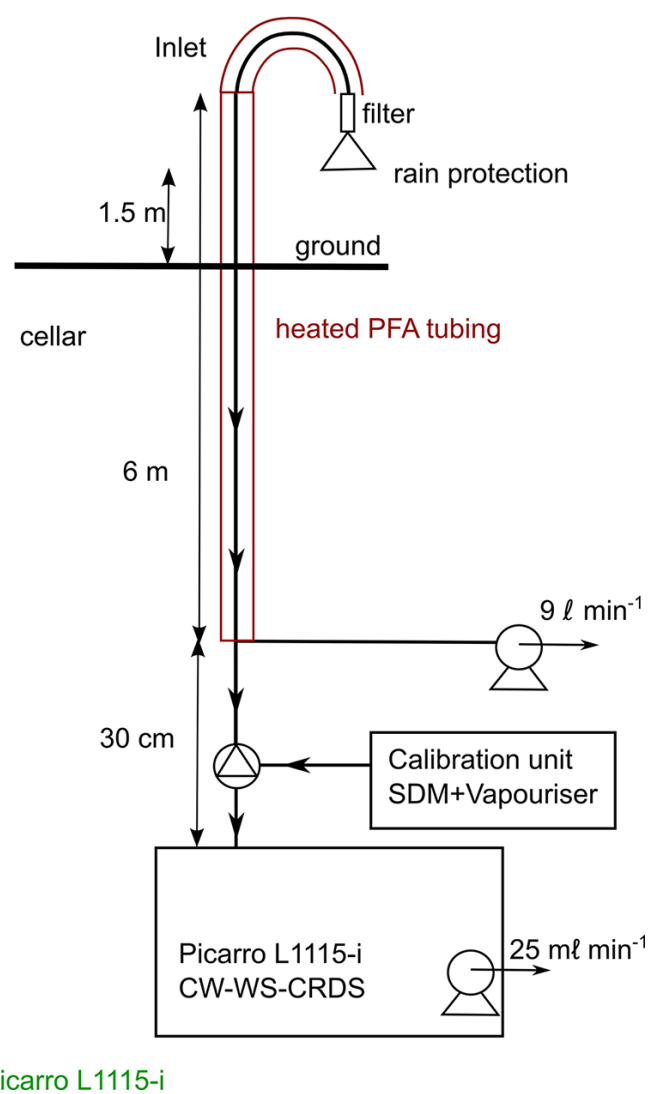

Fig. 2. Setup of the laser spectrometer at the Büel measurement site of the research catchment Rietholzbach. (a) Inlet of the sampling system. (b) Setup of the Picarro L1115-i cavity ring-down laser spectrometer in the cellar of the measurement field. (c) Flow diagram of the setup including the inlet and the laser spectroscopic measurement system.

uptakes, the weights of the previous uptakes are discounted (see Sodemann et al., 2008a, for a detailed description). For each backward trajectory, the meteorological conditions at the uptake points are averaged over all identified uptakes using the weights determined from the specific humidity contribution. For a given measurement, the moisture source information from all 35 (COSMO) or 25 (ERA-Interim) trajectories is averaged, weighted by the specific humidity at each trajectory's starting point.

The moisture source diagnostic was used for both sets of trajectories calculated with the COSMO analyses and the ERA-Interim reanalysis data. Moisture sources were thus obtained every hour using COSMO analysis fields and every $6 \mathrm{~h}$ using ERA-Interim. The sensitivity of our results to the choice of the analysis data is discussed in Appendix D1. Estimates of water residence time in the atmosphere from global model simulations are $\sim 8$ days (Trenberth, 1998). Thus the moisture sources identified with the 10-day backward trajectories calculated with ERA-Interim should largely cover the sources of the moisture sampled at the Rietholzbach site.

An important parameter in the moisture source diagnostic is the maximum altitude at which we consider an uptake to be vertically linked to surface evaporation. Originally this parameter was chosen to be dependent on the boundary layer height (Sodemann et al., 2008a). Detailed inspection of individual cases along our trajectories however show that due to shallow convection air parcels can experience uptakes with a clear vertical link with ground evaporation, even though occurring well above the boundary layer (Aemisegger, 2013). In these cases, the vertical link is due to convective mixing of boundary layer air upward in the atmospheric column. Thus no use of a maximum uptake height for the present study is applied. As shown in Appendix D2, the impact of the choice of the maximum uptake height on our analysis is very small and does not change the interpretation of our results.

\section{Moisture sources and source conditions of the water vapour analysed in Rietholzbach between August and December 2011}

\subsection{Geographical distribution of moisture sources}

In this section, the moisture sources obtained from trajectories calculated with COSMO analyses and ERA-Interim 
a)



c)

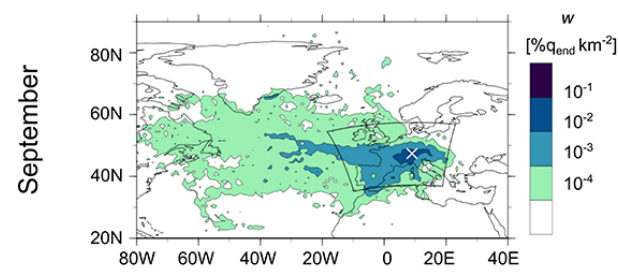

e)

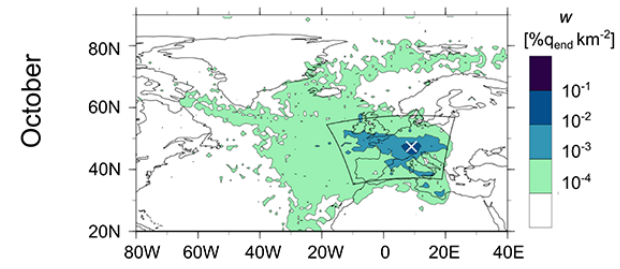

g)

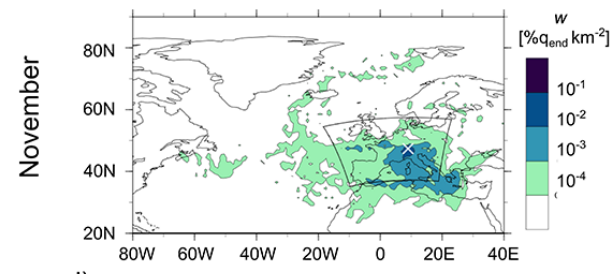

i)

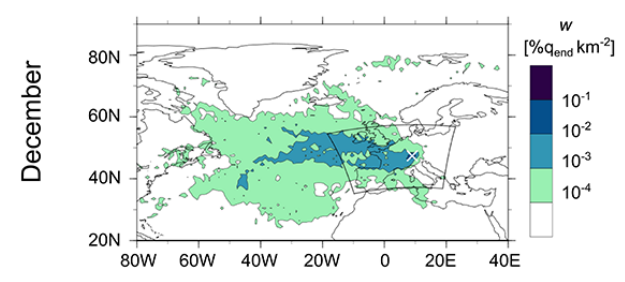

b) $\quad$ COSMO

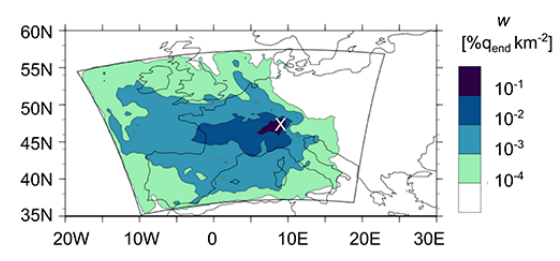

d)

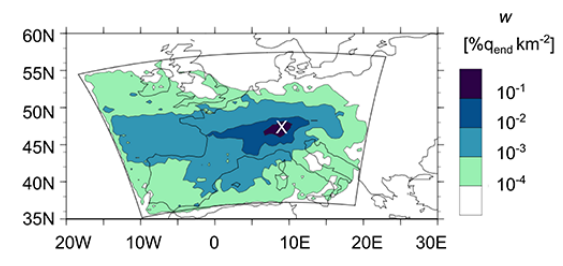

f)

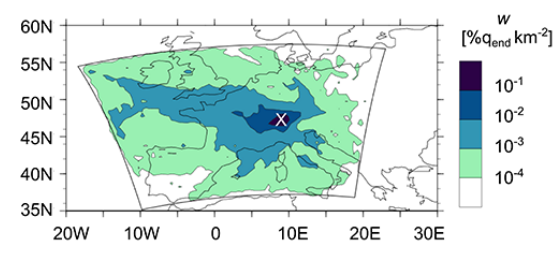

h)

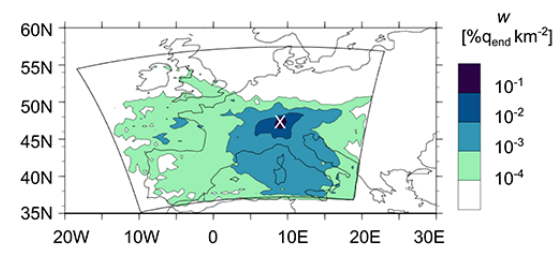

k)

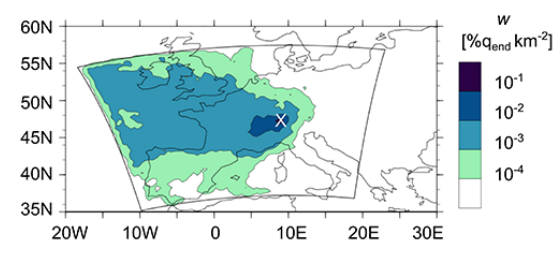

Fig. 3. Monthly average moisture sources between August and December 2011 identified using ERA-Interim (left) and COSMO analyses (right). Colour coding indicates percental contributions to the final specific humidity per $\mathrm{km}^{2}(w)$. The integral over the entire moisture source region sums up to $100 \%$ of the explained moisture at the Rietholzbach site. The white cross indicates the location of the isotope measurement site Rietholzbach. The COSMO domain is indicated by a curved black frame.

reanalyses for the $d$ measurements between August and December 2011 are presented and compared. Figure 3 shows the monthly average moisture sources identified for the measurement period using ERA-Interim (left column) and COSMO analysis data (right column). The panels show the percental contribution per $\mathrm{km}^{2}$ of the moisture sources to the specific humidity at the measurement site. With COSMO, the "explained fraction", i.e., the part of the moisture for which our diagnostic can identify the sources, amounts to $71 \%$. Because of the global domain, this fraction increases when using ERA-Interim data to $88 \%$. When considering only the domain of the regional model, the integrated monthly moisture source distributions between August and December 2011 obtained with ERA-Interim agree very well with those identified with the COSMO analyses. When looking at the global picture, the limitation of the COSMO domain has its largest impact in September, November and December (Fig. $3 c$ versus d, $g$ versus $h$ and i versus k). In September and December the moisture source analysis using the regional model data misses parts of the moisture sources over the 


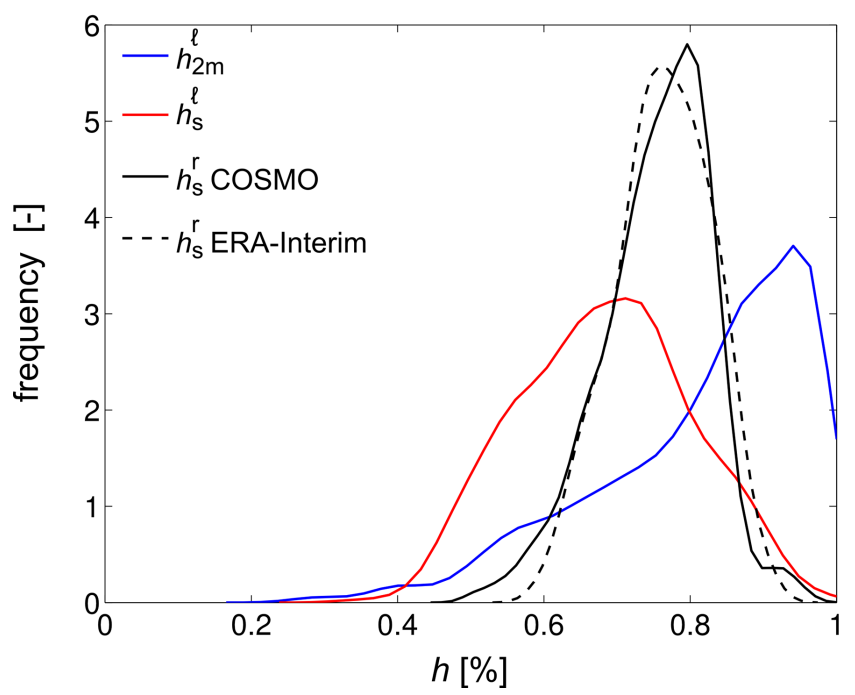

Fig. 4. Distributions of $h_{2 \mathrm{~m}}^{\ell}$ measurements at the Rietholzbach site with respect to $2 \mathrm{~m}$ temperature in blue, $h_{\mathrm{s}}^{\ell}$ measurements with respect to soil temperature $5 \mathrm{~cm}$ below ground in red. The distribution of diagnosed moisture source $h_{\mathrm{s}}^{\mathrm{r}}$ using COSMO analyses is shown by the black solid line, the diagnosed moisture source $h_{\mathrm{s}}^{\mathrm{r}}$ using ERA-Interim data is shown by the black dashed line. All the distributions are shown for the complete data set from August to December 2011.

western Atlantic just outside the model domain. In November (Fig. 3d) the sources in the eastern Mediterranean are outside of the regional model domain. The average distance to the moisture source diagnosed with COSMO for the whole period is $\sim 500 \mathrm{~km}$, whereas this quantity obtained for the same period using ERA-Interim is more than three times larger.

Contributions from ocean evaporation are estimated in the range $10-30 \%$ using COSMO and $35-55 \%$ using ERAInterim. The correlation between the time series of the ocean evaporation contribution based on COSMO and ERAInterim is 0.77 , indicating that even if the exact amplitude is different, the temporal variability of the ocean contribution is similar in the two data sets.

The moisture sources obtained for vapour at the measurement station Rietholzbach between August and December 2011 compare very well in terms of general patterns with the $7 \mathrm{yr}$ climatology of precipitation moisture sources for the Alpine region from January 1995 to August 2002 compiled by Sodemann and Zubler (2010). We also find strong regional moisture recycling over the Alpine region in summer, an important contribution of the Eastern Mediterranean during autumn and predominantly North Atlantic moisture sources in winter. However, the importance of land surface evaporation seems to be much larger in the present study than expected from the climatology. The main reason for this discrepancy might be that precipitation forms at higher altitudes where the remote moisture sources certainly become more important than for the near-ground moisture.
Moisture sources identified with COSMO analyses underestimate the ocean contribution (mainly due to the limited domain), whereas it is possible that the moisture source diagnostics applied to ERA-Interim data overestimates it due to the relatively low temporal and spatial resolution of the data. The interaction between the continental near-surface vapour and the air parcels in ERA-Interim is treated in a coarser way due to the $6 \mathrm{~h}$ temporal and $\sim 1^{\circ}$ spatial resolution.

\subsection{Conditions at the moisture sources}

The conditions at the moisture source were obtained as described in Sect. 3.2 by weighting the individual moisture sources depending on their contribution to the specific humidity of the air parcel at the point of measurement. The statistical properties of $h_{\mathrm{s}}^{\mathrm{r}}$ at the moisture source differ from point measurements of $h_{\mathrm{s}}^{\ell}$.

The $h_{\mathrm{s}}^{\mathrm{r}}$ conditions derived from the moisture source diagnostics (Sect. 3.2) are characterised by lower variability than the locally measured $h_{\mathrm{s}}^{\ell}$ conditions (Fig. 4). The variability in the diagnosed source $h_{\mathrm{s}}^{\mathrm{r}}$ is also smaller than what has previously been found for water vapour sources in Rehovot, Israel (Pfahl and Wernli, 2008). Due to the mixing of different air masses during transport and the spatial extent of the moisture origin, the diagnosed source signals are expected to be smoother than local humidity signals. The distributions of $h_{\mathrm{s}}^{\mathrm{r}}$ at the moisture sources as identified by COSMO and ERAInterim are however very similar.

The distribution of the measured $h_{\mathrm{s}}^{\ell}$ with respect to $T_{\mathrm{s}}^{\ell}$ (red curve in Fig. 4) is shifted towards lower relative humidities compared to the distribution of measured $h_{2 \mathrm{~m}}^{\ell}$ normalised to $T_{2 \mathrm{~m}}^{\ell}$ (blue curve in Fig. 4). This is especially the case in winter and during the night in summer, when the soil is warmer than the air. The regular occurrence of fog leads to very high values of $h_{2 \mathrm{~m}}^{\ell}$ and somewhat lower values of $h_{\mathrm{s}}^{\ell}$. We can exclude any effect of snow cover on the observed difference between $h_{\mathrm{s}}^{\ell}$ and $h_{2 \mathrm{~m}}^{\ell}$, as only a short period with snowfall not resulting in lasting snow cover occurred in December 2011. The relative humidity driving soil evaporation is probably $h_{\mathrm{s}}^{\ell}$. However, for transpiration $h_{2 \mathrm{~m}}^{\ell}$ may better describe the controlling humidity gradient. Since at the daily timescale transpiration does not fractionate, we focus on $h_{\mathrm{s}}$ here to study the effects of soil evaporation on $d$ of continental boundary layer water vapour.

In the following, $d$ measurements in water vapour are interpreted with the diagnosed moisture source conditions from trajectories calculated using COSMO analysis data. The focus of our interest in interpreting $d$ measurements in boundary layer water vapour is on the effects of continental moisture recycling, which justifies the use of the higher-resolution regional model rather than the global model as a basis for the analysis. The sensitivity of our results to the choice of the analysis data set is discussed in Appendix D1. 


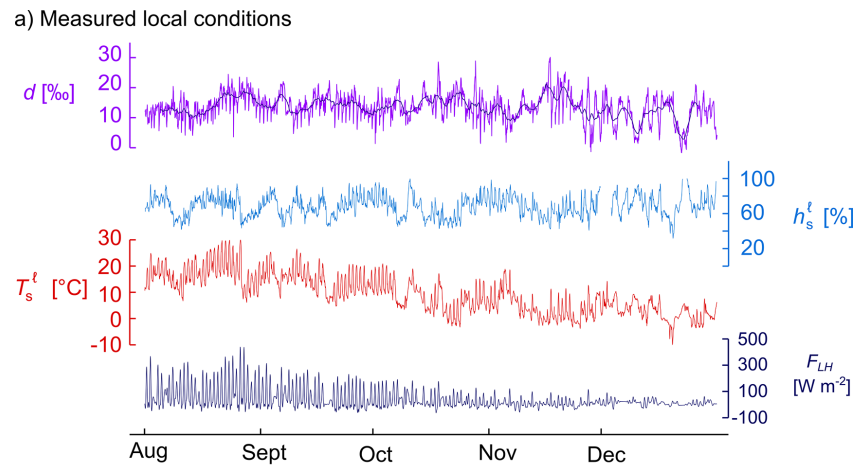

b) Diagnosed remote conditions

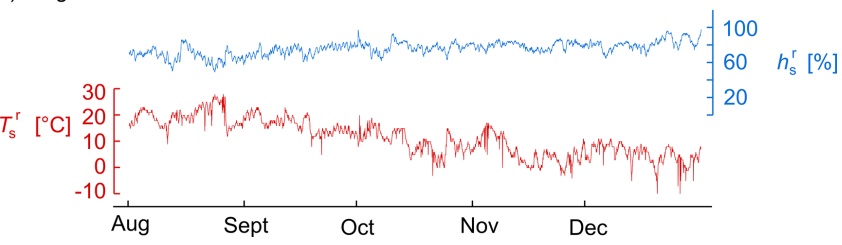

Fig. 5. (a) Time series of hourly averages of $d$ measured in Rietholzbach in violet, moving average over 5 days in dark blue, locally measured $h_{\mathrm{S}}^{\ell}, T_{\mathrm{s}}^{\ell}$ and latent heat flux $F_{\mathrm{LH}} \cdot h_{\mathrm{s}}^{\ell}$ for the local measurements is computed from $2 \mathrm{~m}$ dew point measurements and normalised with respect to $T_{\mathrm{s}}^{\ell}$, where $T_{\mathrm{s}}^{\ell}$ is the soil temperature $5 \mathrm{~cm}$ below ground. (b) Time series of $h_{\mathrm{S}}^{\mathrm{r}}$ and $T_{\mathrm{s}}^{\mathrm{r}}$ diagnosed at the moisture source.

\section{Modes of anticorrelation between $h_{\mathrm{s}}, T_{\mathrm{s}}$ and $d$}

\subsection{Anticorrelation timescale between $d$ and moisture source $h_{\mathrm{s}}^{\mathrm{r}}$ and $T_{\mathrm{s}}^{\mathrm{r}}$}

The hourly $d$ measurement series between August and December 2011 in Fig. 5 shows strong variability between $0 \%$ o and $30 \%$. In summer, fairly clear daily cycles can be distinguished (Fig. 6a). Local processes such as boundary layer mixing, entrainment of free atmospheric air and evapotranspiration (see local latent heat flux in Fig. 5) dominate the variability at the subdaily timescale in the warm season as well as in certain periods of high pressure influence and weak horizontal pressure gradients in autumn (e.g. in late November). The drivers of these local processes have also been discussed in Lai and Ehleringer (2011) and Welp et al. (2012). A second variability component with a timescale of a few days, associated mainly with changing large-scale weather conditions, is indicated by the dark moving average $d$ line in Fig. 5a. This synoptic-scale variability component acts as a low-frequency modulator of the daily $d$ cycle in the warm season and appears to dominate the $d$ signal in autumn and winter (Fig. 6b), when the diurnal variability is reduced. This $d$ variability component is dominated by processes at the remote moisture source (Pfahl and Wernli, 2008; Pfahl and Sodemann, 2014).

When analysing the whole time period at the hourly timescale, $d$ and $h_{\mathrm{s}}^{\ell}$ are not correlated (0.02). In contrast, a)

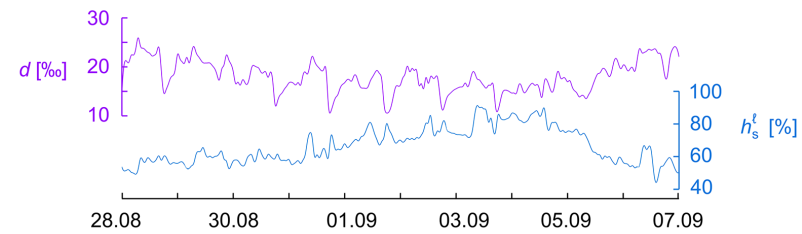

b)



Fig. 6. Close-up of the $d$ time series of Fig. 5a measured at Rietholzbach in violet and $h_{\mathrm{s}}^{\ell}$ (a) respectively $h_{\mathrm{s}}^{r}$ (b) in blue for (a) summer (28.08.2011 to 07.09.2011) and (b) late autumn (02.12.2011 to 10.12 .2011$)$

a weak anticorrelation $(-0.34)$ is found between $d$ and $h_{\mathrm{s}}^{\mathrm{r}}$ as predicted by theory (see Sect. 1 and Fig. 1). This suggests that the average evaporation conditions of the advected moisture have been identified reasonably well using the COSMO trajectories and that remote $h_{\mathrm{s}}^{\mathrm{r}}$ conditions at the moisture sources are more important than local $h_{\mathrm{s}}^{\ell}$ variations to explain the variability of $d$. Thus, this result shows that overall at the hourly timescale the effect of the large-scale moisture sources is more important for the $d$ signal than the effect of local evapotranspiration.

Daily boundary layer mixing processes and local evapotranspiration however affect the strength of the $d-h_{\mathrm{S}}^{\mathrm{r}}$ relationship. The influence of local boundary layer processes, which are essentially regulated by the incoming solar energy and the energy budget at the surface, can be filtered out by using a uniform averaging timescale of $24 \mathrm{~h}$ for $d$. A 5-day moving window correlation between $d$ and $h_{\mathrm{s}}^{\mathrm{r}}$ was computed over the 5 months of $24 \mathrm{~h}$ filtered $d$ data. A window of 5 days for the computation of the moving correlation is regarded as representative for two reasons. On the one hand it reflects the timescale of typical weather situations. On the other hand it makes it possible to treat the data robustly in a statistical sense, which involves keeping a representative number of data points. Slightly shorter and longer time windows for the computation of the moving correlation yield qualitatively similar results.

The $24 \mathrm{~h}$ filtered $d$ and $h_{\mathrm{s}}^{\mathrm{r}}$ for the whole 5-month period are more strongly anticorrelated $(-0.47$, Fig. 7$)$ than the hourly data $(-0.34)$. In the warm season $\left(T_{\mathrm{s}}^{\mathrm{r}}>10^{\circ} \mathrm{C}\right)$, linear regression of the $24 \mathrm{~h}$ filtered signals of $d$ and $h_{\mathrm{s}}^{\mathrm{r}}$ yields a slope of $-0.17 \% \circ \%^{-1}$, which is flatter than the slopes found in the literature and discussed in Sect. 1. In the cold season $\left(T_{\mathrm{s}}^{\mathrm{r}}<10^{\circ} \mathrm{C}\right)$ the $d$ sensitivity on $h_{\mathrm{s}}^{\mathrm{r}}$ is much stronger than in summer with $-0.57 \% \circ \%^{-1}$, which is slightly larger than what Pfahl and Wernli $(2008)\left(-0.53 \% \% \%^{-1}\right)$ and Uemura et al. (2008) $\left(-0.52 \% \%^{-1}\right)$ found for the eastern Mediterranean and the Southern Ocean, respectively. 
a)

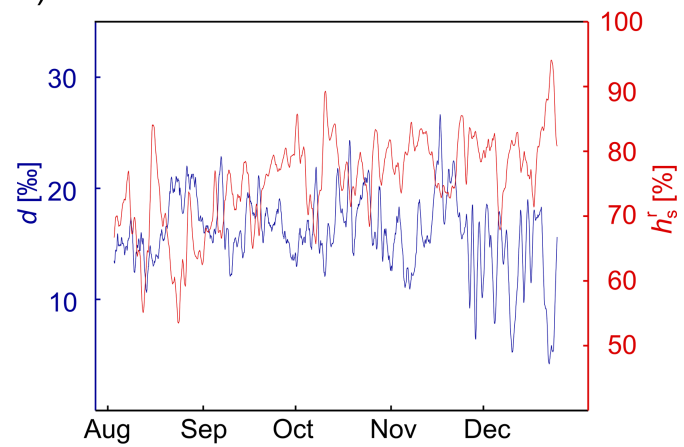

b)

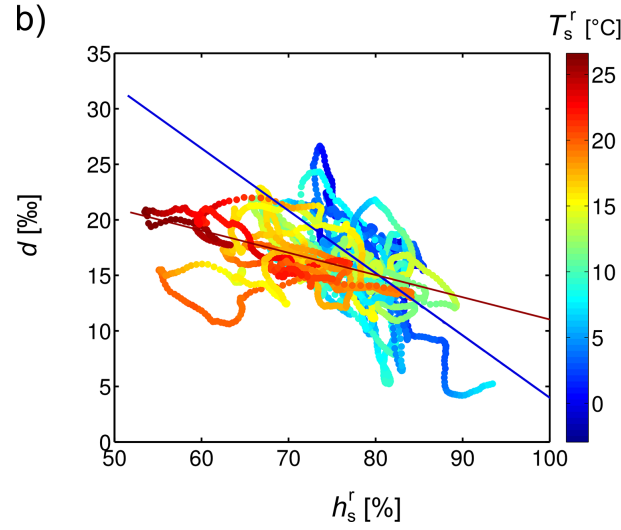

Fig. 7. (a) Time series of $24 \mathrm{~h}$ moving average filtered $d$ signal (blue) measured between August and December 2011 at Rietholzbach and the $24 \mathrm{~h}$ filtered diagnosed source $h_{\mathrm{s}}^{\mathrm{r}}$ using COSMO trajectories (red). (b) Scatter plot for the $d$ and $h_{\mathrm{s}}^{\mathrm{r}}$ signals from panel a. The colour coding indicates skin temperature at the moisture source. The correlation between $d$ and $h_{\mathrm{s}}^{\mathrm{r}}$ is -0.47 . For the cold season $\left(T_{\mathrm{s}}^{\mathrm{r}}<10^{\circ} \mathrm{C}\right)$ linear regression yields $d=-0.57 \cdot h_{\mathrm{s}}^{\mathrm{r}}+61$ (blue line), which implies an average source $d_{\mathrm{s}}^{\mathrm{r}}$ of $4 \%$. For the warm season $\left(T_{\mathrm{s}}^{\mathrm{r}} \geq 10^{\circ} \mathrm{C}\right)$ the linear regression yields $d=-0.19 \cdot h_{\mathrm{s}}^{\mathrm{r}}+30$ with an average source $d_{\mathrm{s}}^{\mathrm{r}}$ of $11 \%$ (red line).

The intersection of the linear regression of $h_{\mathrm{s}}^{\mathrm{r}}$ on $d$ with $h_{\mathrm{s}}^{\mathrm{r}}=100 \%$ provides information on the average $d_{\mathrm{s}}^{\mathrm{r}}$ of the moisture source, as equilibrium fractionation does not alter $d$ (see Appendix A). The average source $d_{\mathrm{s}}^{\mathrm{r}}\left(h_{\mathrm{s}}^{\mathrm{r}}=100 \%\right)$ diagnosed from linear regression in Fig. 7 is smaller in the cold season $(4 \%)$ than in the warm season $(11 \%)$ ). In winter large-scale advection dominates the $d$ variability and continental moisture recycling is weak. In the warm season, the larger $d_{\mathrm{s}}^{\mathrm{r}}$ points towards much stronger continental moisture recycling and less large-scale advection of water vapour directly evaporated from the ocean (for which $d_{\mathrm{s}}^{\mathrm{r}}=d_{\mathrm{o}} \approx 0 \%$ ). Continental recycling increases $d$ as the soil moisture $d_{\mathrm{c}}$ is generally higher than ocean $d_{\mathrm{o}}$ if at least part of the continental evaporation occurs in the form of soil evaporation and if there is loss of soil water by drainage. Otherwise, $d$ for ocean evaporation and evapotranspiration are globally approximately the same. Monthly precipitation samples at the Global Network for Isotopes in Precipitation Network

(GNIP) stations show a $d_{\mathrm{p}}$ of on average around $10 \%$ (Dansgaard, 1964). Knowing that precipitation forms the soil moisture implies higher $d_{\mathrm{s}}^{\ell}$ for the moisture source of land evaporation than for ocean evaporation.

Figure 7 clearly shows that during certain periods the anticorrelation between $d$ and $h_{\mathrm{s}}^{\mathrm{r}}$ is stronger than during other periods. To investigate the effects of moisture advection and recycling on the $24 \mathrm{~h}$ filtered $d-h_{\mathrm{s}}^{\mathrm{r}}$ and $d-h_{\mathrm{s}}^{\ell}$ relationships at the synoptic timescale in more detail, we identified periods which are more strongly affected by remote or local evaporation using the 5-day moving window correlation time series between $d$ and $h_{\mathrm{s}}^{\mathrm{r}}$ respectively $h_{\mathrm{s}}^{\ell}$. This aspect will be analysed and discussed in the next section.

\subsection{Moving window anticorrelations: identification of time periods affected by remote and local evaporation}

The influence of moisture advection on $d$ at the daily timescale is investigated by performing a correlation analysis of $d$ measurements with the diagnosed remote $h_{\mathrm{s}}^{\mathrm{r}}$ and $T_{\mathrm{s}}^{\mathrm{r}}$. The three data series $d, h_{\mathrm{s}}^{\mathrm{r}}$ and $T_{\mathrm{s}}^{\mathrm{r}}$ were uniformly smoothed with a $24 \mathrm{~h}$ filter. The influence of local moisture recycling on $d$ at the daily timescale is analysed using the measured local $h_{\mathrm{s}}^{\ell}$ and $T_{\mathrm{s}}^{\ell}$. In the moisture source diagnostics the contribution of evaporation sites are weighted depending on their contribution to the final humidity of the air parcel. To be consistent with this weighting scheme for the remote sources, we weighted the local $h_{\mathrm{s}}^{\ell}$ and $T_{\mathrm{s}}^{\ell}$ data with the latent heat flux measurements at Rietholzbach when computing the $24 \mathrm{~h}$ moving averages. The results are qualitatively the same as if no such weighting were performed.

In Fig. 8 the 5-day moving window correlations between $d$ and $h_{\mathrm{s}}$ as well as $d$ and $T_{\mathrm{S}}$ are shown. In Fig. 8a, 5-day time periods with $\operatorname{corr}_{5 \mathrm{~d}}\left(h_{\mathrm{s}}^{\mathrm{r}}, d\right) \leq-0.5$ are identified and referred to as high remote anticorrelation (HRA) events. In these cases, the local water vapour carries a distinguishable imprint of the evaporation conditions at remote moisture source locations. In Fig. 8b, 5-day time periods with $\operatorname{corr}_{5 \mathrm{~d}}\left(h_{\mathrm{s}}^{\ell}, d\right) \leq-0.5$ are identified as high local anticorrelation (HLA) events, because the humidity carries the $d$ signal of local to regional evaporation. During HLA periods, the local measurements of $h_{\mathrm{s}}^{\ell}$ and $T_{\mathrm{s}}^{\ell}$ are representative for the conditions of evaporation at the moisture source. The temporal correlation structure of locally measured and diagnosed remote $T_{\mathrm{s}}$ with $d$ as well as $h_{\mathrm{s}}$ with $T_{\mathrm{S}}$ are also shown in Fig. $8 \mathrm{a}$ and $\mathrm{b}$ to investigate the role of $T_{\mathrm{s}}$ for $d$ and to allow the detection of potential cross-correlation effects.

The anticorrelation between $d$ and diagnosed $h_{\mathrm{s}}^{\mathrm{r}}$ at the source identified in Fig. 8a (uppermost axes) strengthens towards autumn and winter. The increasing importance of large-scale moisture advection towards winter and the lower contribution of local evaporation to the regional moisture budget probably explains this strengthening. However, the influence of local evaporation is probably not negligible even 



Fig. 8. (a) Five-day moving window correlation between $24 \mathrm{~h}$ filtered $d$ measurements and moisture source $h_{\mathrm{s}}^{\mathrm{r}}$ and $T_{\mathrm{S}}^{\mathrm{r}}$ conditions. The orange band in the $\operatorname{corr}_{5 \text { day }}\left(h_{\mathrm{s}}^{\mathrm{r}}, d\right)$ plot identifies HRA events. Time periods with $0.5>\operatorname{corr}_{5}$ day $\left(h_{\mathrm{s}}^{\mathrm{r}}, d\right)>-0.5$ are identified as NRA events. The black solid line in the $\operatorname{corr}_{5}$ day $\left(h_{\mathrm{s}}^{\mathrm{r}}, d\right)$ plot represents a linear fit to the moving window correlation curve. The straight blue and red lines show $\operatorname{corr}_{5 \text { day }}\left(T_{\mathrm{s}}^{\mathrm{r}}, d\right)=0$ and $\operatorname{corr}_{5 \text { day }}\left(h_{\mathrm{s}}^{\mathrm{r}}, T_{\mathrm{s}}^{\mathrm{r}}\right)=0$. (b) As in (a) but moving window correlations are shown for local conditions. A few selected HRA and HLA events in (a) and (b) are marked by orange vertical lines (see text for details). The grey vertical line (N) indicates a 5-day period in which we find no anticorrelation of $d$ either with locally measured $h_{\mathrm{s}}^{\ell}$ or with remote $h_{\mathrm{s}}^{\mathrm{r}}$. The dates for the HRA and HLA events are given in Tables 5 and 6, respectively.

in winter (Fig. 5). The same strengthening tendency but with a weaker trend as for the anticorrelation between $d$ and $h_{\mathrm{s}}^{\mathrm{r}}$ is found for the anticorrelation between $d$ and local $h_{\mathrm{s}}^{\ell}$ (Fig. 8b, uppermost axes). This can be explained by the weakening effect of transpiration, which can be assumed to be nonfractionating at the timescale of 1 day (Harwood et al., 1999). Furthermore, the fact that the anticorrelation between local $h_{\mathrm{s}}^{\ell}$ and $d$ is also strong in winter may indicate more homogeneous temperature and humidity conditions over western Europe and the North Atlantic than in the warm season. Indeed the correlation of local $h_{\mathrm{s}}^{\ell}$ and diagnosed remote $h_{\mathrm{s}}^{\mathrm{r}}$ is generally low (0.04) from August to November and somewhat higher (0.3) in December during the concurrent HRA and HLA periods.

During HRA and HLA events, $T_{\mathrm{S}}$ and $d$ are mostly either strongly correlated or anticorrelated (high $\left|\operatorname{corr}_{5 \mathrm{~d}}\left(T_{\mathrm{S}}, d\right)\right|$ ). The fact that the sign of $\operatorname{corr}_{5 \mathrm{~d}}\left(T_{\mathrm{s}}, d\right)$ is changing however shows that there is no consistent relation between $T_{\mathrm{S}}$ and $d$. Furthermore, during HRA or HLA events with high $\left|\operatorname{corr}_{5 \mathrm{~d}}\left(T_{\mathrm{s}}, d\right)\right|$ there is often a strong correlation or anticorrelation signal between $h_{\mathrm{s}}$ and $T_{\mathrm{S}}$ (high $\left|\operatorname{corr}_{5 \mathrm{~d}}\left(h_{\mathrm{s}}, T_{\mathrm{s}}\right)\right|$ ). Crosscorrelation effects with $h_{\mathrm{s}}$ thus probably affect the correlation structure of $T_{\mathrm{s}}$ with $d$. The first and the second HRA events in August (events 1 and 2 in Fig. 8a, see Fig. 9a and $\mathrm{b}$ for the corresponding moisture sources) occur in combination with high $\operatorname{corr}_{5 \mathrm{~d}}\left(T_{\mathrm{s}}^{\mathrm{r}}, d\right)$ and anticorrelated $T_{\mathrm{s}}^{\mathrm{r}}$ and $h_{\mathrm{s}}^{\mathrm{r}}$, which could be related to shallow convection and precipitation at the moisture source locations. In the 10 days preceding HRA events 1 and 2 rain occurred at the moisture source sites according to the European daily precipitation data set (E-OBS; Haylock et al., 2008, not shown). Clouds and precipitation cool the surface and moisten the boundary layer leading to high $h_{\mathrm{s}}$. After the precipitation event, clouds clear up, the ground heats up again and the relative humidity decreases, partly due to the warming, partly due to the reduced humidity input. In winter, in contrast, HRA events occur in combination with highly anticorrelated $T_{\mathrm{s}}^{\mathrm{r}}$ and $d$ and highly correlated $h_{\mathrm{s}}^{\mathrm{r}}$ and $T_{\mathrm{S}}^{\mathrm{r}}$. This pattern is typical over mid-latitude 
a) event 1: 14/08-19/08

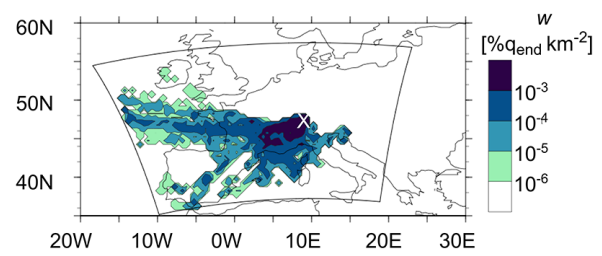

c) event 3: 29/08-03/09

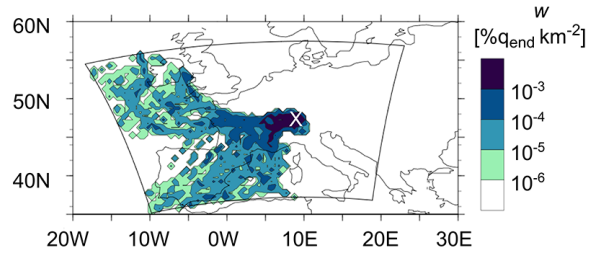

e) event 5: 09/09-14/09



g) event 19: 07/12-12/12



b) event 2: $19 / 08-24 / 08$

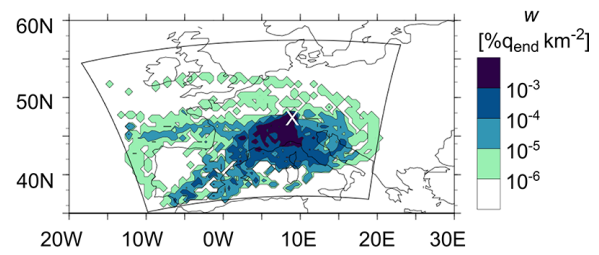

d) event 4: 03/09-08/09

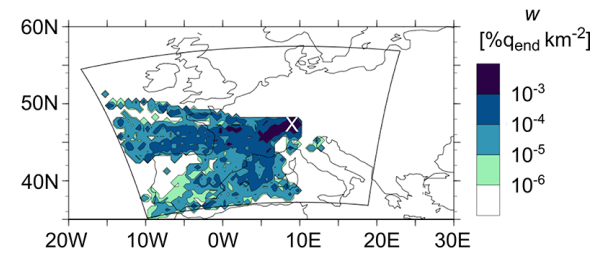

f) event 15: 10/11-15/11

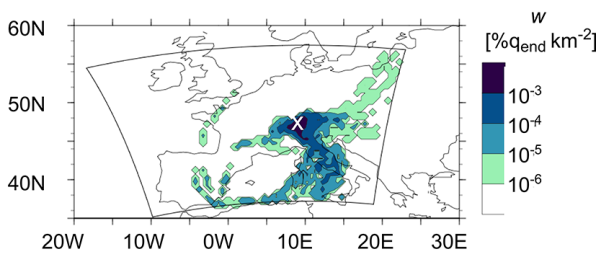

h) event 20: 13/12-18/12



Fig. 9. Integrated moisture sources diagnosed for the HRA events 1 to 5, 15, 19 and 20 discussed in the text. The colour coding indicates percental contribution to the final specific humidity per $\mathrm{km}^{2}(w)$. The integral over the entire moisture source region sums up to $100 \%$ of the explained moisture at the Rietholzbach site (white cross).

ocean regions (Pfahl and Niedermann, 2011) due to the concurrence of cold air advection and subsidence bringing dry air into the boundary layer (HRA events 19 and 20, see Fig. 9g,h for the corresponding moisture source distribution). Warm and moist air advection from the Mediterranean (HRA events 3, 4 and 15, see Fig. 9c,d,g) can also result in high $\operatorname{corr}_{5 \mathrm{~d}}\left(h_{\mathrm{s}}^{\mathrm{r}}, T_{\mathrm{s}}\right)$. Strong changes in the geographical location of the moisture sources over the time frame of a HRA event can be a further cause of high $\operatorname{corr}_{5 \mathrm{~d}}\left(h_{\mathrm{s}}^{\mathrm{r}}, T_{\mathrm{S}}\right)$ if the largescale advection pattern changes from a cold dry region to advection from a warm moist region. Occasionally, when the temperature variability is very small, HRA events occur with no concurrent correlation between $T_{\mathrm{s}}^{\mathrm{r}}$ and $d$ (HRA event 5, Fig. 9).

A further confirmation that $T_{\mathrm{s}}$ may not be a very good proxy for $d$ in our study is the fact that the overall correlation between hourly changes in $d$ and hourly changes in $\delta^{2} \mathrm{H}$ is very small $\left(\operatorname{corr}\left(\frac{\Delta d}{\Delta t}, \frac{\Delta \delta^{2} \mathrm{H}}{\Delta t}\right)=0.01\right.$ for $\left.\Delta t=1 \mathrm{~h}\right)$. The correlation between hourly changes in $d$ and $\delta^{18} \mathrm{O}$ is
$\operatorname{corr}\left(\frac{\Delta d}{\Delta t}, \frac{\Delta \delta^{18} \mathrm{O}}{\Delta t}\right)=-0.3$. The temperature-dependent effect of equilibrium fractionation on $\delta^{2} \mathrm{H}$ is 8 times stronger than that on $\delta^{18} \mathrm{O}$. For $\delta^{18} \mathrm{O}$ the variables controlling the non-equilibrium effect are important, whereas the nonequilibrium effect on $\delta^{2} \mathrm{H}$ is relatively smaller. Thus, variations in $d$ that are mainly driven by large changes in $\delta^{2} \mathrm{H}$ will have a stronger temperature dependency than variations in $d$ that are mainly driven by $h_{\mathrm{s}}$-induced changes in $\delta^{18} \mathrm{O}$. However, variations in $d$ that are mainly driven by changes in $\delta^{18} \mathrm{O}$ should rather reflect $h_{\mathrm{s}}^{\mathrm{r}}$ changes at the moisture source. The higher correlation between the temporal changes in $\delta^{18} \mathrm{O}$ and $d$ than for $\delta^{2} \mathrm{H}$ and $d$ found in our data indicates that $d$ should rather be interpreted as a proxy for $h_{\mathrm{s}}^{\mathrm{r}}$ in this study, which is consistent with the more detailed analysis above.

As shown in Appendix D1, the majority of the HRA events are found both when using COSMO or ERA-Interim data to compute the backward trajectories. The reasons for the identification of a few HRA events only if using COSMO as well as the identification of additional HRA events with ERA-Interim are discussed in Appendix D1. 
Table 4. Median values of the conditions during HRA and NRA events (a) and during HLA and NLA events (b). The ocean moisture source contribution, the source distance, the explained fraction and the specific humidity at the source are properties of the moisture source diagnostics (MSD in the Type column, see Sect. 3.2). The boundary layer height (BLH) was interpolated to the Rietholzbach site from the COSMO model. LH denotes the latent heat flux measured locally at Rietholzbach (indicated by RHB in the Type column). Negative $\mathrm{CO}_{2}$ fluxes are downward. Numbers in bold indicate statistically significant differences between the median of the HRA and NRA distributions in (a) and between HLA and NLA distributions in (b) according to a Wilcoxon rank sum test (Gibbons and Chakraborti, 2011). For the ocean contribution and the source distance the difference is shown only for the cold season as for the whole time period the difference is not significant.

\begin{tabular}{|c|c|c|c|}
\hline \multicolumn{4}{|l|}{ (a) } \\
\hline & HRA & NRA & Type \\
\hline Ocean contribution for $1 \mathrm{Nov}$ to $31 \mathrm{Dec}$ & $28 \%$ & $23 \%$ & MSD \\
\hline Source distance for $1 \mathrm{Nov}$ to $31 \mathrm{Dec}$ & $644 \mathrm{~km}$ & $413 \mathrm{~km}$ & MSD \\
\hline Soil moisture anomaly $5 \mathrm{~cm}$ & $-0.7 \%$ & $-4.2 \%$ & RHB \\
\hline Specific humidity at the source & $9.4 \mathrm{~g} \mathrm{~kg}^{-1}$ & $6.0 \mathrm{~g} \mathrm{~kg}^{-1}$ & MSD \\
\hline Local LH at 11:00-13:00 UTC & $98 \mathrm{Wm}^{-2}$ & $108 \mathrm{Wm}^{-2}$ & RHB \\
\hline Local BLH at 11:00-13:00 UTC & $709 \mathrm{~m}$ & $1500 \mathrm{~m}$ & COSMO \\
\hline \multicolumn{4}{|l|}{ (b) } \\
\hline & HLA & NLA & Type \\
\hline Soil moisture anomaly $5 \mathrm{~cm}$ & $3.1 \%$ & $-4.2 \%$ & RHB \\
\hline Cumulative precipitation & $453 \mathrm{~mm}$ & $312 \mathrm{~mm}$ & RHB \\
\hline $10 \mathrm{~m}$ wind & $1.4 \mathrm{~ms}^{-1}$ & $0.9 \mathrm{~ms}^{-1}$ & RHB \\
\hline $\mathrm{CO}_{2}$ flux for 1.8 to 30.9 at $11: 00-13: 00$ UTC & $-0.75 \mathrm{mg} \mathrm{m}^{-2} \mathrm{~s}^{-1}$ & $-0.81 \mathrm{mg} \mathrm{m}^{-2} \mathrm{~s}^{-1}$ & RHB \\
\hline BLH at 11:00-13:00 UTC & $818 \mathrm{~m}$ & $620 \mathrm{~m}$ & COSMO \\
\hline
\end{tabular}

\subsection{Differences between anticorrelation and no-anticorrelation events}

HRA and HLA events can occur simultaneously in some cases (e.g. HRA event 4 and HLA event 7 in Fig. 8a and b) if the local $h_{\mathrm{s}}^{\ell}$ variations are representative for the moisture source region. HLA event 1 occurs during a period with no correlation between the diagnosed moisture source $h_{\mathrm{s}}^{\mathrm{r}}$ and the measured $d$. Periods such as HLA event 1 can clearly be identified as being influenced by local processes.

Periods without anticorrelation of $d$ with locally measured $h_{\mathrm{s}}^{\ell}$ (referred to as no local anticorrelation, NLA, events) or with remote $h_{\mathrm{s}}^{\mathrm{r}}$ (no remote anticorrelation events, NRA) can be found over several successive 5-day periods (see e.g. grey line in Fig. 8). In summer and early autumn, these periods may be associated with a very high transpiration contribution to the land surface latent heat flux, which lowers the sensitivity of $d$ to $h_{\mathrm{S}}$ as it can be assumed to be non-fractionating over the timescale of 1 day (see also Sect. 6). In November such periods of concurrent NLA and NRA could be associated with shorter typical correlation time periods than 5 days or strongly changing day-to-day moisture source $d_{\mathrm{s}}^{\mathrm{r}}$, which alters the characteristics of the $d-h_{\mathrm{s}}$ relation. In principle, periods of no correlation between $d$ and remote $h_{\mathrm{s}}^{\mathrm{r}}$ may also occur due to errors in the Lagrangian moisture source analysis or due to additional influences on $d$ such as strong belowcloud evaporation of precipitation.
During HRA events, the dominance of large-scale advection to the site of isotope measurements over local boundary layer processes and local recycling is also reflected by smaller latent heat flux as well as a smaller boundary layer height at the measurement site compared to NRA events (Table 4a). Furthermore, local soil moisture at the Rietholzbach measurement site during HRA events indicates much dryer conditions than during HLA events. During the cold season, HRA events are connected to more distant moisture sources and higher ocean contribution.

Specific humidity at the evaporation site (Table 4a) indicates wetter conditions during uptake for HRA periods than during NRA periods. In summer and over land, recent rainfall can lead to a temporal reduction of transpiration and stronger contribution of soil evaporation (Yepez et al., 2005; Shim et al., 2013). This aspect is confirmed by the analysis of the characteristics of the HLA events. The $5 \mathrm{~cm}$ soil moisture and local precipitation during HLA events is higher than in the case of NLA events (Table 4b). Moist soil conditions at the measurement site thus strengthen the $d-h_{\mathrm{s}}^{\ell}$ relation, due to stronger bare soil evaporation and weaker transpiration. This hypothesis is underlined by the lower local downward $\mathrm{CO}_{2}$ flux in summer and early autumn (reflecting reduced transpiration) during HLA events than during NLA events. Furthermore, during HLA events, the local boundary layer dynamics seems to be stronger than during NLA or HRA events with higher boundary layer heights and stronger winds pointing 
towards an enhanced atmospheric forcing of local evaporation (Table 4b).

At our site, moisture source $h_{\mathrm{s}}^{\mathrm{r}}$, local boundary layer dynamics, the partitioning of the latent heat flux over land into soil evaporation and plant transpiration as well as precipitation seem to play a key role in determining the $d$ signal of continental water vapour at the daily timescale. The role of precipitation in influencing the strength and properties of the $d-h_{\mathrm{s}}$ relationship is fourfold:

1. In a quantitative sense, the amount and frequency of occurrence of precipitation determines the wetness of the soil. Mathieu and Bariac (1996) suggested the use of larger non-equilibrium fractionation factors $\left(\alpha_{\mathrm{c}}^{\mathrm{k}}\right)$ for dry than for wet soils (see also Table 1). Differences in soil wetness and thus in the non-equilibrium fractionation factor can lead to differences in the properties of the $d-h_{\mathrm{S}}$ relationship as will be discussed in Sect. 6 .

2. The occurrence of precipitation may play an important role for HRA and HLA events in summer as mentioned above in the discussion of Table $4 \mathrm{a}$ and $\mathrm{b}$, due to its momentary effect of reducing transpiration (Yepez et al., 2005; Shim et al., 2013).

3. Precipitation $d$ determines $d_{\mathrm{c}}$ of the soil moisture. The global average $d_{\mathrm{p}}$ of precipitation is about $10 \%$ (Dansgaard, 1964). Recycled moisture from continental origin can produce precipitation samples with $d>$ $10 \%$. This can affect the intercept of the $d-h_{\mathrm{s}}$ relationship, as will be discussed in Sect. 6 .

4. The type of weather system producing precipitation is relevant in determining the $d$ signature of precipitation. The moisture source area of moisture uptakes is very different for frontal or cyclonic precipitation than for purely convective or orographic precipitation systems (Barras and Simmonds, 2009; Guan et al., 2013). This is an interesting topic for future research.

\section{The $d-h_{\mathrm{s}}$ relation for moisture affected by continental recycling}

The $d-h_{\mathrm{s}}^{\mathrm{r}}$ scatter plot for all HRA events shown in Fig. 10 reveals 5 to $10 \%$ higher $d$ values for the same $h_{\mathrm{s}}^{\mathrm{r}}$ than in the relation found by Pfahl and Wernli (2008) in a region with a dominant ocean evaporation contribution. The generally higher $d$ values can be attributed to continental moisture recycling, which increases the $d$ of moisture by repeated bare soil evaporation from soil water that typically has higher $d$ compared to ocean water (see also Sect. 5.1).

A clear seasonal tendency can be identified in the properties of the $d-h_{\mathrm{s}}^{\mathrm{r}}$ relationship in Fig. 10 (see also Table 5). In the warm season the slope is smaller with values between $-0.16 \% \%^{-1}$ and $-0.58 \% \circ \%^{-1}$ (Table 5), compared

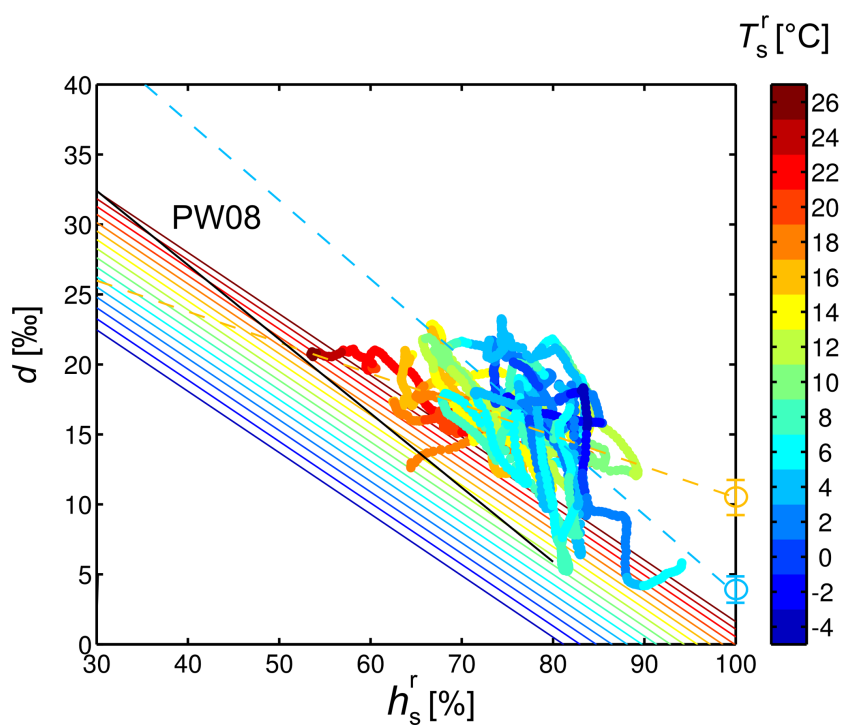

Fig. 10. The $d-h_{\mathrm{s}}^{\mathrm{r}}$ relations for HRA events. The colour bar indicates diagnosed ground temperature $T_{\mathrm{s}}^{\mathrm{r}}$ at the point of evaporation. The solid coloured and black lines are as in Fig. 1. The dashed orange line represents the linear regression of the $d$ measurements against the moisture source $h_{\mathrm{s}}^{\mathrm{r}}$ for $T_{\mathrm{s}}^{\mathrm{r}} \geq 10^{\circ} \mathrm{C}: d=-0.22 \cdot h_{\mathrm{s}}^{\mathrm{r}}+33$ and thus a source $d_{\mathrm{s}}^{\mathrm{r}}$ of $11 \%$ o. The dashed blue line represents the linear regression of the $d$ measurements using the moisture source $h_{\mathrm{S}}^{\mathrm{r}}$ in winter for $T_{\mathrm{S}}^{\mathrm{r}}<10^{\circ} \mathrm{C}: d=-0.56 \cdot h_{\mathrm{s}}^{\mathrm{r}}+60$ and thus a source $d_{\mathrm{s}}^{\mathrm{r}}$ of $4 \%$.

to $-0.19 \% \%^{-1}$ for $T_{\mathrm{s}}^{\mathrm{r}}>10^{\circ} \mathrm{C}$ for the overall data series of $24 \mathrm{~h}$ filtered data. In the cold season the slope is between $-0.25 \% \%^{-1}$ and $-1.10 \% \%^{-1}$ (Table 5), compared to $-0.57 \% \%^{-1}$ for $T_{\mathrm{s}}^{\mathrm{r}}<10{ }^{\circ} \mathrm{C}$ for the overall data series of $24 \mathrm{~h}$ filtered data. The extrapolated source $d_{\mathrm{s}}^{\mathrm{r}}\left(\right.$ at $\left.h_{\mathrm{s}}^{\mathrm{r}}=100 \%\right)$ for HRA events is on average around 7\%o in summer and around 2\%o in winter (Fig. 10 and Table 5). In summer and fall the $d-h_{\mathrm{s}}^{\mathrm{r}}$ relation of continental moisture strongly depends on the contribution of transpiration. For an increasing fraction of transpiration to the total evapotranspiration flux, assuming transpiration to be non-fractionating, the $d$ $h_{\mathrm{s}}^{\mathrm{r}}$ slope becomes flatter (compare the orange and light blue dashed lines in Fig. 10). In the cold season transpiration is reduced and the evapotranspiration flux largely consists of soil evaporation. The intra-seasonal variability in the $d-h_{\mathrm{s}}^{\mathrm{r}}$ slopes and intercept is probably due to the variable contributions of transpiration and the changing soil moisture properties impacting the moisture source $d_{\mathrm{s}}^{\mathrm{r}}$ and the non-equilibrium fractionation factors, which differ for wet and dry soils (Mathieu and Bariac, 1996). Below-cloud interaction of precipitation with ambient water vapour is another process that can influence the $d-h_{\mathrm{s}}^{\mathrm{r}}$ slopes and intercept by depleting the surrounding water vapour of heavy isotopes. Post-condensational exchange can thus lead to an increase of $d$ in vapour during light rainfall at $h<100 \%$ (Field et al., 2010). 
Table 5. Slope and intercept of $d-h_{\mathrm{s}}^{\mathrm{r}}$ for HRA events. The whole HRA data set is shown in Fig. 10 in a $d-h_{\mathrm{s}}^{\mathrm{r}}$ scatter plot. The columns show the date of the events, the slope, the diagnosed source $d_{\mathrm{s}}^{\mathrm{r}}$, the mean ground temperature and the ocean contribution $f_{\mathrm{o}}$ during the events (obtained from the moisture source diagnostic). $f_{\mathrm{t}}$ shows the transpiration fraction of the evapotranspiration flux over the continental part of the moisture source region (see Sect. 7 for more details). The statistical significance level for the slope obtained by linear regression was checked using a $t$ test with a $98 \%$ confidence interval. The $p$ value for the regressions of all the events is smaller than 0.001 .

\begin{tabular}{lccrccc}
\hline HRA event & Date & Slope $\left[\% \%^{-1}\right]$ & $d_{\mathrm{s}}^{\mathrm{r}}[\%$ o $]$ & $T_{\mathrm{s}}^{\mathrm{r}}\left[{ }^{\circ} \mathrm{C}\right]$ & $f_{\mathrm{o}}[\%]$ & $f_{\mathrm{t}}[\%]$ \\
\hline 1 & 14 Aug to 19 Aug & $-0.16 \pm 0.01$ & $11 \pm 1$ & 19.5 & 16 & 89 \\
2 & 19 Aug to 24 Aug & $-0.35 \pm 0.01$ & $6 \pm 1$ & 23.2 & 13 & 68 \\
3 & 29 Aug to 03 Sep & $-0.36 \pm 0.06$ & $5 \pm 4$ & 18.1 & 17 & 70 \\
4 & 03 Sep to 08 Sep & $-0.51 \pm 0.07$ & $3 \pm 5$ & 18.6 & 21 & 57 \\
5 & 09 Sep to 14 Sep & $-0.37 \pm 0.06$ & $5 \pm 4$ & 18.4 & 19 & 69 \\
6 & 15 Sep to 20 Sep & $-0.26 \pm 0.04$ & $10 \pm 3$ & 15.2 & 15 & 78 \\
7 & 20 Sep to 25 Sep & $-0.35 \pm 0.06$ & $9 \pm 4$ & 13.5 & 7 & 67 \\
8 & 25 Sep to 30 Sep & $-0.58 \pm 0.10$ & $3 \pm 8$ & 13.7 & 4 & 49 \\
9 & 01 Oct to 06 Oct & $-0.19 \pm 0.01$ & $11 \pm 1$ & 13.5 & 6 & 79 \\
10 & 06 Oct to 11 Oct & $-0.31 \pm 0.02$ & $8 \pm 2$ & 12.1 & 28 & 81 \\
11 & 11 Oct to 16 Oct & $-0.34 \pm 0.05$ & $11 \pm 5$ & 10.8 & 26 & 77 \\
12 & 21 Oct to 26 Oct & $-0.25 \pm 0.04$ & $14 \pm 3$ & 6.0 & 18 & 83 \\
13 & 27 Oct to 01 Nov & $-0.45 \pm 0.08$ & $5 \pm 6$ & 7.5 & 12 & 61 \\
14 & 02 Nov to 07 Nov & $-0.76 \pm 0.08$ & $-2 \pm 6$ & 12.9 & 39 & 30 \\
15 & 10 Nov to 15 Nov & $-0.44 \pm 0.05$ & $8 \pm 4$ & 4.1 & 8 & 60 \\
16 & 18 Nov to 23 Nov & $-0.25 \pm 0.03$ & $15 \pm 3$ & 3.7 & 20 & 85 \\
17 & 24 Nov to 29 Nov & $-0.67 \pm 0.11$ & $1 \pm 9$ & 2.1 & 15 & 43 \\
18 & 02 Dec to 07 Dec & $-0.30 \pm 0.05$ & $7 \pm 4$ & 7.8 & 36 & 87 \\
19 & 07 Dec to 12 Dec & $-0.83 \pm 0.07$ & $-7 \pm 6$ & 7.7 & 40 & 21 \\
20 & 13 Dec to 18 Dec & $-0.60 \pm 0.10$ & $1 \pm 7$ & 5.4 & 33 & 50 \\
21 & 18 Dec to 23 Dec & $-1.1 \pm 0.05$ & $-5 \pm 5$ & 2.3 & 27 & 0 \\
\hline
\end{tabular}

When selecting only HRA data with a direct contribution of ocean evaporation of more than $50 \%$ the sensitivity of $d$ to changes in $h_{\mathrm{s}}^{\mathrm{r}}$ is $-0.28 \% \circ \%^{-1}$. The continental moisture contribution for these events is still between $20 \%$ and $50 \%$, which explains the weaker slope and the larger offset $\left(d_{\mathrm{s}}^{\mathrm{r}}=36 \%\right.$ o $)$ than in the study of Pfahl and Wernli (2008) $(-0.52 \% 0 \%-1)$.

The relationship between $d$ and locally measured $h_{\mathrm{s}}^{\ell}$ for HLA events shown in Fig. 11 also exhibits a seasonal cycle in the $d-h_{\mathrm{s}}^{\ell}$ slopes (see also Table 6). In summer the $d-h_{\mathrm{s}}^{\ell}$ slopes of the HLA events are similar to the HRA $d-h_{\mathrm{s}}^{r}$ slopes (around $-0.15 \% \%^{-1}$ ). However, for the HLA events associated with cold temperatures the $d-h_{\mathrm{s}}^{\ell}$ slopes remain rather small, with a maximum negative value of $-0.35 \% \%^{-1}$ in December. The smaller $d-h_{\mathrm{s}}^{\ell}$ slopes for HLA events (compared to $d-h_{\mathrm{s}}^{\mathrm{r}}$ slopes for HRA events) may be explained by higher local non-equilibrium fractionation factors (i.e., $\alpha_{\mathrm{c}}^{\mathrm{k}}$ values), by a non-negligible contribution of transpiration even in winter and the intense recycling process of moisture condensing and freezing on the grass and soil during night and evaporating again during daytime. In the cold season, the source $d_{\mathrm{s}}^{\ell}$ for HLA events are higher than for HRA events. The 2-weekly measurements of $d$ in the soil moisture (outflow of the lysimeter, Table A1) are comparable to the $d_{\mathrm{s}}^{\ell}$ diagnosed here for HLA events (Table 6), even though the 2-weekly samples of course show a smoothed signal.

\section{Estimates of the transpiration fraction of continental evaporation from the $d-h_{\mathrm{s}}$ relation}

The $d-h_{\mathrm{s}}$ relation obtained from boundary layer $d$ measurements and the Lagrangian moisture source identification scheme provides a novel and useful framework to partition the continental evaporation flux into transpiration and soil evaporation. As already discussed, the slope of the $d-h_{\mathrm{s}}$ relation depends on the contribution of transpiration, soil evaporation and ocean evaporation. The theoretical slope of the $d-h_{\mathrm{s}}$ relation of continental evaporation (Fig. 12a) can be computed using the Craig and Gordon (1965) model under the following assumptions:

1. The only source for boundary layer water vapour is surface evaporation (closure assumption, see Appendix A for more details; Merlivat and Jouzel, 1979) A sensitivity study on how the closure assumption is applied (on each evaporation flux separately or globally) is given in Appendix C. Furthermore, as mentioned in Sect. 1 , the $d-h_{\mathrm{s}}$ slope may be overestimated when applying the closure assumption (Jouzel and Koster, 1996). This implies that we may in turn slightly underestimate the transpiration fraction with our approach. 
Table 6. Slope and intercept of $d-h_{\mathrm{s}}^{\ell}$ relation for HLA events. The whole HLA data set is shown in Fig. 11 in a $d-h_{\mathrm{s}}^{\ell}$ scatter plot. The columns show the date of the events, the slope, the diagnosed source $d_{\mathrm{s}}^{\ell}$ (local soil moisture $d$ signature) and the mean ground temperature. $f_{\mathrm{t}}$ shows the transpiration fraction of the evapotranspiration flux at the Rietholzbach measurement site (see Sect. 7 for more details). The ocean contribution for HLA events is set to $f_{\mathrm{o}}=0$ as the moisture source is assumed to be local. The statistical significance level for the slope obtained by linear regression was checked using a $t$ test with a $98 \%$ confidence interval. The $p$ value for the regressions of all the events is smaller than 0.001 .

\begin{tabular}{lccrcc}
\hline Event & Date & Slope $\left[\% \%^{-1}\right]$ & $d_{\mathrm{s}}^{\ell}[\%$ o $]$ & $T_{\mathrm{s}}^{\ell}\left[{ }^{\circ} \mathrm{C}\right]$ & $f_{\mathrm{t}}[\%]$ \\
\hline 1 & 03 Aug to 08 Aug & $-0.06 \pm 0.01$ & $14 \pm 1$ & 18.9 & 86 \\
2 & 08 Aug to 13 Aug & $-0.19 \pm 0.03$ & $6 \pm 2$ & 18.0 & 75 \\
3 & 16 Aug to 21 Aug & $-0.20 \pm 0.03$ & $12 \pm 2$ & 19.7 & 74 \\
4 & 21 Aug to 26 Aug & $-0.06 \pm 0.01$ & $18 \pm 1$ & 20.4 & 86 \\
5 & 26 Aug to 31 Aug & $-0.25 \pm 0.03$ & $9 \pm 2$ & 17.5 & 71 \\
6 & 31 Aug to 05 Sep & $-0.07 \pm 0.01$ & $15 \pm 1$ & 18.3 & 84 \\
7 & 05 Sep to 10 Sep & $-0.14 \pm 0.02$ & $8 \pm 1$ & 17.7 & 70 \\
8 & 14 Sep to 19 Sep & $-0.07 \pm 0.01$ & $16 \pm 1$ & 17.1 & 85 \\
9 & 30 Sep to 05 Oct & $-0.14 \pm 0.02$ & $13 \pm 2$ & 15.3 & 79 \\
10 & 05 Oct to 10 Oct & $-0.16 \pm 0.02$ & $10 \pm 1$ & 13.1 & 78 \\
11 & 10 Oct to 15 Oct & $-0.21 \pm 0.01$ & $10 \pm 1$ & 13.1 & 74 \\
12 & 21 Oct to 26 Oct & $-0.14 \pm 0.02$ & $15 \pm 2$ & 8.8 & 80 \\
13 & 26 Oct to 31 Oct & $-0.18 \pm 0.03$ & $12 \pm 2$ & 9.1 & 77 \\
14 & 05 Nov to 10 Nov & $-0.29 \pm 0.05$ & $8 \pm 4$ & 10.0 & 68 \\
15 & 10 Nov to 15 Nov & $-0.21 \pm 0.02$ & $10 \pm 1$ & 8.5 & 75 \\
16 & 04 Dec to 09 Dec & $-0.08 \pm 0.02$ & $5 \pm 2$ & 5.5 & 84 \\
17 & 09 Dec to 14 Dec & $-0.32 \pm 0.02$ & $2 \pm 2$ & 5.3 & 67 \\
18 & 14 Dec to 19 Dec & $-0.35 \pm 0.03$ & $8 \pm 2$ & 4.8 & 65 \\
19 & 19 Dec to 24 Dec & $-0.24 \pm 0.01$ & $5 \pm 1$ & 3.7 & 73 \\
20 & 24 Dec to 29 Dec & $-0.18 \pm 0.02$ & $6 \pm 1$ & 2.1 & 77 \\
\hline
\end{tabular}

2. Transpiration is assumed to directly transmit the signature of the soil moisture, which is assumed to be constant over the 5-day time period of a HRA or HLA event.

3. $h_{\mathrm{s}}$ and the isotope ratio of liquid soil water $\left(R_{\mathrm{c}}\right)$ represent average conditions at the moisture source for each time step.

Using these assumptions the ${ }^{18} \mathrm{O} /{ }^{16} \mathrm{O}$ and the ${ }^{2} \mathrm{H} /{ }^{1} \mathrm{H}$ ratio of boundary layer water vapour can be expressed as (see Appendix $\mathrm{B}$ for the derivation)

$R_{\mathrm{v}}=\frac{f_{\mathrm{o}} \frac{R_{\mathrm{o}}}{\alpha_{\mathrm{o}}^{\mathrm{k}} \alpha\left(1-h_{\mathrm{s}}\right)}+\left(1-f_{\mathrm{o}}\right)\left[f_{\mathrm{t}} R_{\mathrm{c}}+\left(1-f_{\mathrm{t}}\right) \frac{R_{\mathrm{c}}}{\alpha_{\mathrm{c}}^{\mathrm{k}} \alpha\left(1-h_{\mathrm{s}}\right)}\right]}{1+f_{\mathrm{o}} \frac{h_{\mathrm{s}}}{\alpha_{\mathrm{o}}^{\mathrm{k}}\left(1-h_{\mathrm{s}}\right)}+\left(1-f_{\mathrm{o}}\right)\left(1-f_{\mathrm{t}}\right) \frac{h_{\mathrm{s}}}{\alpha_{\mathrm{c}}^{\mathrm{k}}\left(1-h_{\mathrm{s}}\right)}}$,

where $R_{\mathrm{v}}$ is the isotope ratio of boundary layer water vapour, $R_{\mathrm{O}}$ the isotope ratio of ocean water, $R_{\mathrm{c}}$ the isotope ratio of continental surface water, $f_{\mathrm{o}}$ the contribution of ocean evaporation to the continental low-level moisture, $f_{\mathrm{t}}$ the transpiration fraction of continental evaporation, $\alpha$ the equilibrium fractionation factor, $\alpha_{\mathrm{o}}^{\mathrm{k}}$ the non-equilibrium fractionation factor for ocean water, $\alpha_{\mathrm{c}}^{\mathrm{k}}$ the non-equilibrium fractionation factor for soil evaporation and $h_{\mathrm{s}}$ the relative humidity at the moisture source. The $f_{\mathrm{o}}$ is known from the moisture source diagnostics. Transpiration is assumed to be the only non-fractionating evaporation flux at the timescale of 1 day.
The linear relation between the $d-h_{\mathrm{S}}$ slope and the transpiration fraction obtained in this way (Fig. 12b) is very sensitive to the non-equilibrium fractionation factor in the Craig and Gordon (1965) model. As shown in Table 1 and discussed in several recent publications (Braud et al., 2009b; Haverd and Cuntz, 2010; Soderberg et al., 2012) large uncertainties are associated with the non-equilibrium fractionation factors for soil evaporation. This is the most important source of error associated with the transpiration fraction estimation method presented here. It is illustrated in Fig. 12b using different literature values for the non-equilibrium fractionation factor. Because we only use the slope of the $d-h_{\mathrm{S}}$ relation, no information on the soil moisture $d_{\mathrm{c}}$ is needed. Changes in the soil moisture isotopic composition induce a parallel shift of the $d-h_{\mathrm{S}}$ relation and do not affect the slope.

To obtain the transpiration fractions for each HRA and HLA event, the theoretical linear relation between the $d-$ $h_{\mathrm{S}}$ slope and the transpiration fraction is computed using Eq. (3). In the case of HRA events the average ocean evaporation fraction for each event is obtained from the moisture source diagnostics. For HLA events the ocean evaporation fraction is set to 0 .

We used the non-equilibrium fractionation factors for wet soils of Mathieu and Bariac (1996) for soil evaporation and those of Pfahl and Wernli (2009) (see Table 1) for ocean evaporation to obtain the transpiration fraction estimates 


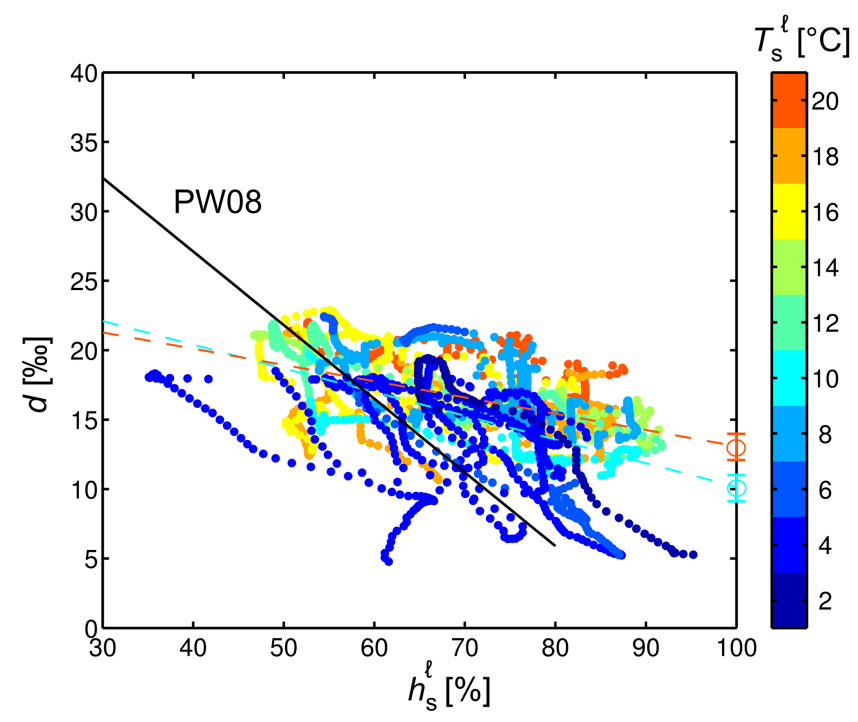

Fig. 11. The $d-h_{\mathrm{s}}^{\ell}$ relations of HLA events. The colour bar indicates ground temperature $T_{\mathrm{S}}^{\ell}$. The dashed red line represents a fit to the data for $T_{\mathrm{s}}^{\ell} \geq 10^{\circ} \mathrm{C}: d=-0.12 \cdot h_{\mathrm{s}}^{\ell}+25$ and thus a diagnosed local soil moisture $d_{\mathrm{s}}^{\ell}$ of $13 \%$ in the Rietholzbach area. The dashed blue line represents a fit to the data for $T_{\mathrm{s}}^{\ell}<10^{\circ} \mathrm{C}: d=-0.17 \cdot h_{\mathrm{s}}^{\ell}+27$ and thus a diagnosed local soil moisture $d_{\mathrm{S}}^{\ell}$ of $10 \%$ in the Rietholzbach area. The black line shows the empirical relationship of Pfahl and Wernli (2008).

shown in Tables 5 and 6, because they are probably representative for the moisture sources of HRA events with a dominance of evaporation from western and central Europe as well as for Rietholzbach for the transpiration part estimates during HLA events.

The transpiration fractions of continental evapotranspiration obtained from the $d-h_{\mathrm{s}}$ slopes of the 21 HRA events (Table 5) and the 20 HLA events (Table 6) lie within the range of values presented in other studies using isotope measurements (Moreira et al., 1997; Yepez et al., 2003; Williams et al., 2004; Robertson and Gazis, 2006; Zhang et al., 2010; Sutanto et al., 2012; Jasechko et al., 2013) or from GCM modelling (Lawrence et al., 2007). The event-to-event variability of the transpiration fraction associated with the different HRA events is large and varies between 0 and $89 \%$ with an average value of $62 \%$. These values are very sensitive to the non-equilibrium fractionation factors and increase with larger $\alpha_{\mathrm{c}}^{\mathrm{k}}$ (see Fig. 12b as well as the sensitivity study in Appendix C). The sensitivity of the transpiration fraction estimates obtained using Eq. (3) with respect to different nonequilibrium fractionation factors for soil evaporation is much more important than the way that the closure assumption is applied. When using the non-equilibrium fractionation factor for dry soils of Mathieu and Bariac (1996) we obtain an average transpiration fraction for HRA events of $73 \%$ with a minimum value of $31 \%$. Particularly for low transpiration fractions, when soil evaporation is strong, the choice of the non-equilibrium fractionation factor becomes very important.

Applying our transpiration fraction estimation method to HLA events (Table 6) yields higher transpiration fractions due to the flatter $d-h_{\mathrm{S}}$ slopes than for HRA events, as discussed in Sect. 6. Averaged over all HLA events we find a transpiration fraction of $76 \%$ with values between $65 \%$ and $86 \%$ for the individual events. When using the nonequilibrium fractionation factor for dry soils of Mathieu and Bariac (1996) we obtain an average transpiration fraction for HLA events of $82 \%$. Other non-fractionating local moisture sources like intercept evaporation, dew formation and reevaporation might also have contributed to these large transpiration fractions for Rietholzbach. This could be particularly important in late autumn and winter when the contribution of plant transpiration is expected to be close to zero. Entrainment of free tropospheric air may be a further confounding factor, as it brings dry air with low $h$ and large $d$ values into the boundary layer. Neglecting this effect in the analysis of HLA events is a strong assumption, which should be studied in more detail in the future. Furthermore, the grasslanddominated local land use at the Rietholzbach measurement site probably induces higher transpiration fractions than during HRA events, for which evaporation from large parts of continental Europe with a land use combination of crop land, forest and grassland contribute to the sampled water vapour (Teuling et al., 2010). This may also contribute to explaining the lower values and the larger variability of the transpiration fraction for HRA events than for HLA events.

There are two main differences between our approach and evapotranspiration partitioning methods based on an isotope mass balance at the measurement site (see review by Zhang et al., 2010). Firstly, by combining a Lagrangian moisture source diagnostic tool with local $d$ measurements we propose a framework to estimate the evapotranspiration partitioning over the whole footprint region of continental evaporation for time periods during which large-scale moisture advection dominates over local evapotranspiration. This approach could be useful for model verification as it provides regionally integrated estimates of the transpiration fraction (in the case of HRA events). Secondly, we do not need to apply an isotope mass balance at the measurement site to obtain the partitioning, in contrast to the traditional evapotranspiration partitioning methods using isotopes.

The values of the transpiration fraction found here over 5 months of $d$ measurements are generally lower than the global estimates of $80-90 \%$ on average presented in a recent study by Jasechko et al. (2013) using isotope measurements from lake catchments in various regions. The transpiration fractions found here show that even though the transpiration fraction of continental evaporation can be very high, especially in summer, the event-to-event variability is substantial. Clearly, because different timescales are considered (i.e., daily data here versus annual data in Jasechko et al., 2013) a direct comparison of our estimates with those from 
a)

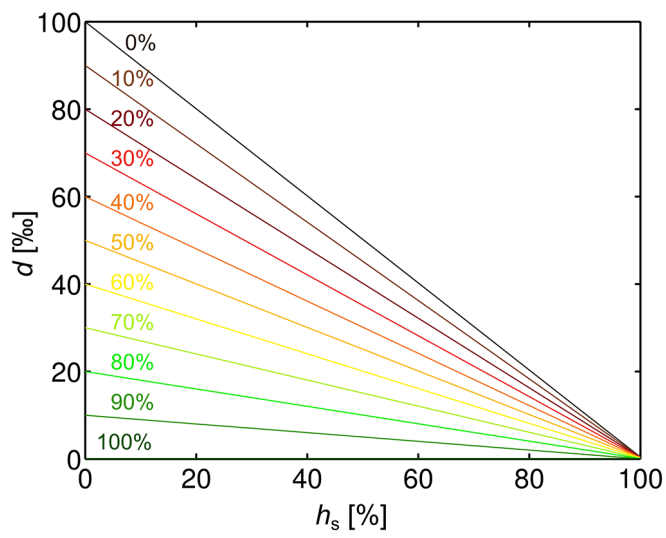

b)

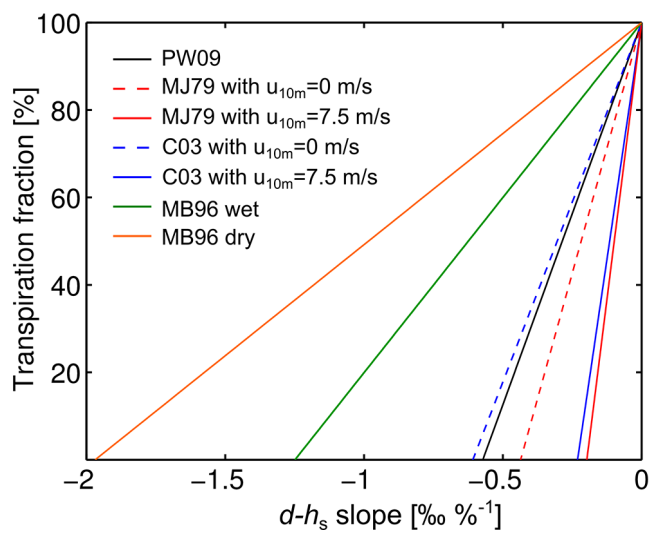

Fig. 12. (a) The $d-h_{\mathrm{S}}$ relations obtained using the Craig and Gordon (1965) evaporation model assuming closure for different fractions of transpiration contributions to continental evaporation (colours). The non-equilibrium fractionation factors for wet soils (see Table 1, Mathieu and Bariac, 1996) were used here. (b) Theoretical linear relationship between the transpiration fraction and the slope of the $d-h_{\mathrm{S}}$ relation using the Craig and Gordon (1965) evaporation model and applying the closure assumption for $T_{\mathrm{s}}=25^{\circ} \mathrm{C}$. The different lines correspond to the use of different non-equilibrium fractionation factors. PW09 stands for Pfahl and Wernli (2009), MJ79 for Merlivat and Jouzel (1979), C03 for Cappa et al. (2003), and MB96 for Mathieu and Bariac (1996). For the estimates of the transpiration fraction in Tables 5 and 6 the non-equilibrium factors for wet soils (see Table 1, Mathieu and Bariac, 1996) are used for soil evaporation and the non-equilibrium fractionation factors of Pfahl and Wernli (2009) are applied for ocean evaporation.

Jasechko et al. (2013) is difficult. Furthermore, no estimates can be done for NRA or NLA events with our approach. For many of the NRA and NLA events, especially in summer, the high transpiration fraction is supposed to be responsible for the absence of anticorrelation between $d$ and $h_{\mathrm{s}}$. However, like for the traditional isotope mass balance based methods (Zhang et al., 2010), some assumptions used in Jasechko et al. (2013) should be further investigated, particularly the assumptions involved in computing the isotopic composition of the soil evaporation flux to explain the very high values of $d$ in the soil evaporation flux (75\%), the role of the nonequilibrium fractionation factor, and the influence of the isotopic signature of ambient water vapour in contrast to using the equilibrium vapour isotopic composition from precipitation isotope measurements.

In future research a comparison of the transpiration fraction estimates obtained here with traditional isotope mass balance methods as well as with estimates from regional climate models could provide further constraints for the robust modelling of the land surface evaporation components. Specific simulations of HRA events using isotopeenabled numerical weather prediction models would allow us to perform sensitivity experiments on the importance of the non-equilibrium fractionation factor for soil evaporation and eventually help to better constrain this important parameter. Furthermore, the importance of other non-fractionating evaporation fluxes like intercept or dew evaporation should be investigated. From the experimental side, controlled chamber or soil column experiments of soil evaporation for different soil moisture contents using the advantages of the novel laser measurement techniques are critical to reduce the uncertainty associated with the non-equilibrium fractionation factor.

\section{Conclusions}

In this paper, we presented 5 months of hourly laser spectrometric measurements of $d$ in the continental boundary layer in northeastern Switzerland. Earlier studies revealed that $d$ measurements in a marine environment are a good proxy for $h_{\mathrm{S}}$ at the evaporation site of the moisture (Gat et al., 2003; Pfahl and Wernli, 2008; Uemura et al., 2008). Our goal in this study was to find out whether continental moisture affected by land surface recycling processes still can be used as a tracer for evaporation conditions at the source. We interpreted our $d$ measurements using local $h_{\mathrm{s}}^{\ell}$ and $T_{\mathrm{s}}^{\ell}$ measurements as well as a Lagrangian moisture source diagnostic providing $h_{\mathrm{s}}^{\mathrm{r}}$ and $T_{\mathrm{s}}^{\mathrm{r}}$ conditions integrated over the evaporation source region.

We found that at the hourly to daily timescale $d$ measurements were strongly influenced by boundary layer mixing of local evapotranspiration and water vapour in the free atmosphere. These processes are driven by the daily cycle of the incoming solar energy. At a longer timescale ( $\geq 1$ day), this daily cycle of $d$ is modulated by large-scale advection of moisture from land surface and ocean evaporation with a generally larger footprint than the local evapotranspiration source.

Using a 5-day running window correlation of $d$ with $h_{\mathrm{s}}^{\mathrm{r}}$ as well as with $h_{\mathrm{s}}^{\ell}$ for $24 \mathrm{~h}$ filtered data, events of strong anticorrelation between $d$ and $h_{\mathrm{s}}^{\mathrm{r}}$ (HRA) as well as between $d$ and $h_{\mathrm{s}}^{\ell}$ 
(HLA) could be identified. The temporal correlation pattern of the diagnosed $h_{\mathrm{s}}^{\mathrm{r}}$ at the moisture source and the measured $d$ signal in Rietholzbach revealed different modes of strong anticorrelation between moisture source $h_{\mathrm{s}}^{\mathrm{r}}$ and $d$ measurements. These modes can be explained by either a higher than normal contribution of ocean sources or the dominance of soil evaporation over plant transpiration. Periods with a weak or absent relationship between the $d$ and the source $h_{\mathrm{s}}^{\mathrm{r}}$ coincide with periods and source locations that are probably characterised by the dominance of plant transpiration. The clear seasonal pattern in the properties of the $d-h_{\mathrm{s}}^{\mathrm{r}}$ link for both diagnosed source $h_{\mathrm{s}}^{\mathrm{r}}$ and local $h_{\mathrm{s}}^{\ell}$ support this hypothesis. With the decreasing importance of plant transpiration as well as local boundary layer dynamics towards winter and increasing importance of large-scale advection, the strength of the 5-day moving average anticorrelation between $d$ and $h_{\mathrm{s}}^{\mathrm{r}}$ increases.

We found that $T_{\mathrm{S}}$ is a secondary predictor of $d$. On the one hand it indirectly characterises the seasonality of the $d-$ $h_{\mathrm{s}}$ relationship, being a proxy for transpiration intensity. On the other hand it plays a role through cross-correlation effects between $T_{\mathrm{S}}$ and $h_{\mathrm{s}}$. Furthermore, $\operatorname{corr}_{5 \text { day }}\left(d, T_{\mathrm{S}}\right)$ more often showed strongly negative values rather than positive ones as would be expected if the small temperature effect on $d$ through the equilibrium fractionation factor played an important role.

Due to the stronger influence of transpiration in the warm season, we found a weaker sensitivity of $d$ to changes in $h_{\mathrm{s}}^{\mathrm{r}}$ at the moisture source in summer $\left(\sim-0.2 \% \%^{-1}\right)$ than in winter. The $d-h_{\mathrm{s}}^{\mathrm{r}}$ relations found for oceanic settings in the literature are larger $\left(\sim-0.5 \% \%^{-1}\right)$ due to the absence of moisture from plant transpiration. In the cold season, however, the sensitivity of $d$ to changes in $h_{\mathrm{s}}^{\mathrm{r}}$ at the moisture source is larger than for oceanic settings $\left(\sim-0.6 \% \%^{-1}\right)$. This is probably due to stronger non-equilibrium fractionation for soil evaporation than for ocean evaporation. The effect of precipitation on the $d$ signature of continental evaporation is central. It modulates the soil moisture $d_{\mathrm{c}}$ and indirectly impacts the strength of the non-equilibrium fractionation via the soil wetness.

The characteristics of the $d-h_{\mathrm{s}}^{\mathrm{r}}$ relationship may be a useful proxy for attributing ambient water vapour to ocean evaporation, soil evaporation and plant transpiration, even though the uncertainties associated with this attribution method are still large. The transpiration fractions of continental evaporation estimated from the $d-h_{\mathrm{s}}^{\mathrm{r}}$ slopes obtained in this study show a strong case-to-case variability. For continental Europe during HRA events we found average transpiration fractions of $62 \%$ for the 5-month time period between August and December 2011. Higher values of on average $76 \%$ were found for the grassland measurement site of Rietholzbach during HLA events and are probably due to the difference in dominant land use. As the estimates from other isotope methods for the separation of the evapotranspiration flux, the transpiration fractions obtained in this study are associated with important assumptions and uncertainties that have to be addressed in future research. Particularly the validity of the closure assumption and the effect of entrainment and boundary layer dynamics should be studied in detail in future work. The non-equilibrium fractionation factor used in the Craig and Gordon (1965) model for soil evaporation is another important source of uncertainty. Future studies investigating the variability of this factor as a function of soil conditions (wetness and temperature) could help to provide better constraints for the estimate of the transpiration fraction and for the representation of land surface evaporation in isotope-enabled numerical models.

Finally, our results show that despite the generally intense mixing processes in the atmospheric boundary layer a detectable imprint of the evaporation conditions of the water vapour remains present in its isotopic composition. This highlights the potential use of $d$ measurements as a tool for the study of evaporation conditions over land and ocean as well as its role as a proxy for circulation patterns.

Acknowledgements. We are grateful to Camille Risi and an anonymous referee for their detailed and constructive reviews. We thank MeteoSwiss for providing COSMO analysis data and ERA-Interim reanalyses, Karl Schroff for technical help in setting up the isotope measurements at the Rietholzbach measurement site and Roland Werner for the IRMS measurements of the 2-weekly soil moisture samples.

Edited by: T. Röckmann

\section{References}

Aemisegger, F.: Atmospheric stable water isotope measurements at the timescale of extratropical weather systems, Ph.D. thesis, no. 21165, Institute for Atmospheric and Climate Science, ETH Zurich, 242 pp., Zurich, Switzerland, 2013.

Aemisegger, F., Sturm, P., Graf, P., Sodemann, H., Pfahl, S., Knohl, A., and Wernli, H.: Measuring variations of $\delta^{18} \mathrm{O}$ and $\delta^{2} \mathrm{H}$ in atmospheric water vapour using two commercial laserbased spectrometers: an instrument characterisation study, Atmos. Meas. Tech., 5, 1491-1511, doi:10.5194/amt-5-1491-2012, 2012.

Anker, Y., Flexer, A., Rosenthal, E., and Ganor, E.: Relationship between the origin of precipitation in the Jordan Rift valley and their geochemical composition, J. Geophys. Res., 112, D03306, doi:10.1029/2006JD007517, 2007.

Barras, V. J. I. and Simmonds, I.: Synoptic controls upon $\delta^{18} \mathrm{O}$ in southern Tasmanian precipitation, Geophys. Res. Lett., 35, L02707, doi:10.1029/2007GL031835, 2008.

Barras, V. and Simmonds, I.: Observation and modelling of stable water isotopes as diagnostics of rainfall dynamics over southeastern Australia, J. Geophys. Res., 114, D23308, doi:10.1029/2009JD012132, 2009.

Betts, A. K.: Understanding hydrometeorology using global models, B. Am. Meteorol. Soc., 85, 1673-1688, doi:10.1175/BAMS85-11-1673, 2004. 
Bigleisen, J.: Statistical mechanics of isotope effects on the thermodynamic properties of condensed systems, J. Chem. Phys., 34, 1485-1493, doi:10.1063/1.1701033, 1961.

Boé, J. and Terray, L.: Uncertainties in summer evapotranspiration changes over Europe and implications for regional climate change, Geophys. Res. Lett., 35, L05702, doi:10.1029/2007GL032417, 2008.

Bosilovich, M. G., Schubert, S. D., and Walker, G. K.: Global changes of the water cycle intensity, J. Climate, 18, 1591-1608, doi:10.1175/JCLI3357.1, 2005.

Braud, I., Biron, P., Bariac, T., Richard, P., Canale, L., Gaudet, J. P., and Vauclin, M.: Isotopic composition of bare soil evaporated water vapor. Part I: RUBIC IV experimental setup and results, J. Hydrol., 369, 1-16, doi:10.1016/j.jhydrol.2009.01.034, 2009a.

Braud, I., Bariac, T., Biron, P., and Vauclin, M.: Isotopic composition of bare soil evaporated water vapor. Part II: Modeling of RUBIC IV experimental results, J. Hydrol., 369, 17-29, doi:10.1016/j.jhydrol.2009.01.038, 2009b.

Cappa, C. D., Hendricks, M. B., DePaolo, D. J., and Cohen, R. C.: Isotopic fractionation of water during evaporation, J. Geophys. Res., 108, 4525, doi:10.1029/2003JD003597, 2003.

Ciais, P. and Jouzel, J.: Deuterium and oxygen 18 in precipitation: isotopic model, including mixed cloud processes. J. Geophys. Res., 99, 16793-16803, doi:10.1029/94JD00412, 1994.

Craig, H.: Isotopic variations in meteoric waters, Science, 133, 1702-1703, doi:10.1126/science.133.3465.1702, 1961.

Craig, H. and Gordon, L. I.: Deuterium and oxygen 18 variations in the ocean and marine atmosphere, in: Stable Isotopes in Oceanographic Studies and Paleotemperature, edited by: Tongiorgi, E., Consiglio nazionale delle ricerche, Laboratorio di geologia nucleare, Spoleto, Italy, Pisa, 9-130, 1965.

Dansgaard, W.: Stable isotopes in precipitation, Tellus, 16, 436468, doi:10.1111/j.2153-3490.1964.tb00181.x, 1964.

Dee, D. P., Uppala, S. M., Simmons, A. J., Berrisford, P., Poli, P., Kobayashi, S., Andrae, U., Balmaseda, M. A., Balsamo, G., Bauer, P., Bechtold, P., Beljaars, A. C. M., van de Berg, L., Bidlot, J., Bormann, N., Delsol, C., Dragani, R., Fuentes, M., Geer, A. J., Haimberger, L., Healy, S. B., Hersbach, H., Hólm, E. V., Isaksen, L., Kållberg, P., Köhler, M., Matricardi, M., McNally, A. P., Monge-Sanz, B. M., Morcrette, J.-J., Park, B.-K., Peubey, C., de Rosnay, P., Tavolato, C., Thépaut, J.-N., and Vitart, F.: The ERA-Interim reanalysis: configuration and performance of the data assimilation system, Q. J. Roy. Meteor. Soc., 137, 553-597, doi:10.1002/qj.828, 2011

Doms, G. and Schättler, U.: A description of the nonhydrostatic regional model LM, part I: dynamics and numerics, Deutscher Wetterdienst, Offenbach, Germany, 2002.

Douville, H., Ribes, A., Decharme, B., Alkama, R., and Sheffield, J.: Anthropogenic influence on multidecadal changes in reconstructed global evapotranspiration, Nature Climate Change, 3, 59-62, doi:10.1038/nclimate1632, 2013.

Entekhabi, D. and Eagleson, P. S.: Land surface hydrology parameterization for atmospheric general circulation models including subgrid scale spatial variability, J. Climate, 2, 816-831, doi:10.1175/1520-0442(1989)002<0816:LSHPFA>2.0.CO;2, 1989.

Farquhar, G. D., Cernusak, L. A., and Barnes, B.: Heavy water fractionation during transpiration, Plant Physiol., 143, 11-18, doi:10.1104/pp.106.093278, 2007
Field, R. D., Jones, D. B. A., and Brown, D. P.: Effects of post-condensation exchange on the isotopic composition of water in the atmosphere, J. Geophys. Res., 115, D24305, doi:10.1029/2010JD014334, 2010.

Gat, J. R.: Oxygen and hydrogen isotopes in the hydrological cycle, Annu. Rev. Earth Pl. Sc., 24, 225-262, doi:10.1146/annurev.earth.24.1.225, 1996.

Gat, J. R., Klein, B., Kushnir, Y., Roether, W., Wernli, H., Yam, R., and Shemesh, A.: Isotope composition of air moisture over the Mediterranean Sea: an index of air-sea interaction pattern, Tellus B, 55, 953-965, doi:10.1034/j.1600-0889.2003.00081.x, 2003.

Gat, J. R. and Matsui, E.: Atmospheric water balance in the Amazon basin: An isotopic evapotranspiration model, J. Geophys. Res, 96, 13179-13188, doi:10.1029/91JD00054, 1991.

Gibbons, J. D. and Chakraborti, S.: Nonparametric Statistical Inference, 5th edn., edited by: Balakrishnan, N. and Schucany, W. R., Chapman \& Hall, CRC Press, Taylor \& Francis Group, 2011.

Guan, H., Zhang, X., Skrzypek, G., Sun, Z., and Xu, X.: Deuterium excess variations of rainfall events in a coastal area of South Australia and its relationship with synoptic weather systems and atmospheric moisture sources, J. Geophys. Res., 118, 1123-1138, doi:10.1002/jgrd.50137, 2013.

Harwood, K. G., Gillon, J. S., Roberts, A., and Griffiths, H.: Determinants of isotopic coupling of $\mathrm{CO}_{2}$ and water vapour within a Quercus petraea forest canopy, Oecologia, 119, 109-119, doi:10.1007/s004420050766, 1999.

Haverd, V. and Cuntz, M.: Soil-litter-iso: a one-dimensional model for coupled transport of heat, water and stable isotopes in soil with a litter layer and root extraction, J. Hydrol., 388, 438-455, doi:10.1016/j.jhydrol.2010.05.029, 2010.

Haylock, M. R., Hofstra, N., Klein Tank, A. M. G., Klok, E. J., Jones, P. D., and New, M.: A European daily highresolution gridded data set of surface temperature and precipitation 1950-2006, J. Geophys. Res., 113, D20119, doi:10.1029/2008JD010201, 2008.

Held, I. M. and Soden, B. J.: Robust responses of the hydrological cycle to global warming, J. Climate, 19, 5686-5699, doi:10.1175/JCLI3990.1, 2006.

Hoffmann, G., Werner, M., and Heimann, M.: Water isotope module of the ECHAM atmospheric general circulation model: a study on timescales from days to several years, J. Geophys. Res., 103, 167871-16896, doi:10.1029/98JD00423, 1998.

Horita, J. and Wesolowski, D. J.: Liquid-vapour fractionation of oxygen and hydrogen isotopes of water from the freezing to the critical temperature, Geochim. Cosmochim. Ac., 58, 3425-3437, doi:10.1016/0016-7037(94)90096-5, 1994.

IAEA: Reference Sheet for VSMOW2 and SLAP2 international measurement standards, International Atomic Energy Agency, (IAEA), 2009.

Jasechko, S., Sharp, Z. D., Gibson, J. J., Birks, S. J., Yi, Y., and Fawcett, P. J.: Terrestrial water fluxes dominated by transpiration, Nature, 496, 347-351, doi:10.1038/nature11983, 2013.

Johnsen, S. J., Dansgaard, W., and White, J. W. C.: The origin of Arctic precipitation under present and glacial conditions, Tellus B, 41, 452-468, doi:10.1111/j.1600-0889.1989.tb00321.x, 1989.

Joussaume, S., Sadourny, R., and Jouzel, J.: A general circulation model of water isotope cycles in the atmosphere, Nature, 311, 24-29, doi:10.1038/311024a0, 1984. 
Jouzel, J. and Koster, R. D.: A reconsideration of the initial conditions used for stable water isotope models, J. Geophys. Res., 101, 22933-22938, doi:10.1029/96JD02362, 1996.

Jouzel, J. and Merlivat, L.: Deuterium and oxygen 18 in precipitation: modeling of the isotopic effects during snow formation, J. Geophys. Res., 89, 11749-11757, doi:10.1029/JD089iD07p11749, 1984.

Jouzel, J., Stiévenard, M., Johnsen, S. J., Landais, A., Masson-Delmotte, A. Sveinbjörnsdottir, A., Vimeux, F., von Grafenstein, U., and White, J. W, C.: The GRIP deuterium-excess record, Quaternary Sci. Rev., 26, 1-17, doi:10.1016/j.quascirev.2006.07.015, 2007.

Jung, M., Reichstein, M., Ciais, P., Seneviratne, S. I., Sheffield, J., Goulden, M. L., Bonan, G., Cescatti, A., Chen, J., de Jeu, R., Dolman, A. J., Eugster, W., Gerten, D., Gianelle, D., Gobron, N., Heinke, J., Kimball, J., Law, B. E, Montagnani, L., Mu, Q., Mueller, B., Oleson, K. Papale, D., Richardson, A. D., Roupsard, O., Running, S., Tomelleri, E., Viovy, N., Weber, U., Williams, C., Wood, E., Zaehle, S., and Zhang, K.: Recent decline in the global land evapotranspiration trend due to limited moisture supply, Nature, 467, 951-954, doi:10.1038/nature09396, 2010.

Koster, R. D., Dirmeyer, P. A., Guo, Z., Bonan, G., Chan, E., Cox, P., Gordon, C. T., Kanae, S., Kowalczyk, E., Lawrence, D., Liu, P., Lu, C.-H., Malyshey, S., McAvaney, B., Mitchell, K., Mocko, D., Oki, T., Oleson, K., Pitman, A., Sud, Y. C., Taylor, C. M., Verseghy, D., Vasic, R., Xue, Y., and Yamada, T.: Regions of strong coupling between soil moisture and precipitation, Science, 305, 1138-1140, doi:10.1126/science.1100217, 2004.

Lai, C.-T. and Ehleringer, J. R.: Deuterium excess reveals diurnal sources of water vapor in forest air. Oecologia, 165, 213-223, doi:10.1007/s00442-010-1721-2, 2011.

Lawrence, J. R., Gedzelman, S. D., Dexheimer, D., Cho, H.K., Carrie, G. D., Gasparini, R., Anderson, C. R., Bowman, K. P., and Biggerstaff, M. I.: Stable isotopic composition of water vapor in the tropics, J. Geophys. Res., 109, D06115, doi:10.1029/2003JD004046, 2004.

Lawrence, D. M., Thornton, P. E., Oleson, K. W., and Bonan, G. B.,: The partitioning of evapotranspiration into transpiration, soil evaporation, and canopy evaporation in a GCM: impacts on land-atmosphere interaction, J. Hydrometeorol., 8, 862-880, doi:10.1175/JHM596.1, 2007.

Lee, X., Griffis, T. J. , Baker, J. M., Billmark, K. A., Kim, K., and Welp, L. R.: Canopy-scale kinetic fractionation of atmospheric carbon dioxide and water vapor isotopes, Global Biogeochem. Cy., 23, GB1002, doi:10.1029/2008GB003331, 2009.

Majoube, M.: Fractionnement en oxygène- 18 et en deutérium entre l'eau et sa vapeur, J. Chim. Phys., 68, 1423-1436, 1971.

Mathieu, R. and Bariac, T.: A numerical model for the simulation of stable isotope profiles in drying soils, J. Geophys. Res., 101, 12685-12696, doi:10.1029/96JD00223, 1996.

Merlivat, L.: The dependence of bulk evaporation coefficients on air-water interfacial conditions as determined by the isotopic method, J. Geophys. Res., 83, 2977-2980, doi:10.1029/JC083iC06p02977, 1978.

Merlivat, L. and Jouzel, J.: Global Climatic interpretation of the deuterium excess-oxygen 18 relationship for precipitation, J. Geophys. Res., 84, 5029-5033, doi:10.1029/JC084iC08p05029, 1979.
Moreira, M., Sternberg, L., Martinelli, L., Victoria, R., Barbosa, E., Bonates, L., and Nepstad, D.: Contribution of transpiration to forest ambient vapour based on isotopic measurements, Glob. Change Biol., 3, 439-450, doi:10.1046/j.13652486.1997.00082.x, 1997.

Mueller, B. and Seneviratne, S. I.: Hot days induced by precipitation deficits at the global scale, P. Natl. Acad. Sci. USA, 109, 1239812403, doi:10.1073/pnas.1204330109, 2012.

Petit, J. R., White, J. W. C., Young, N. W., Jouzel, J., and Korotkevich, Y. S.: Deuterium excess in recent Antarctic snow, J. Geophys. Res., 96, 5113-5122, doi:10.1029/90JD02232, 1991.

Pfahl, S. and Niedermann, N.: Daily covariations in near-surface relative humidity and temperature over the ocean, J. Geophys. Res., 116, D19104, doi:10.1029/2011JD015792, 2011.

Pfahl, S. and Sodemann, H.: What controls deuterium excess in global precipitation?, Clim. Past, 10, 771-781, doi:10.5194/cp10-771-2014, 2014.

Pfahl, S. and Wernli, H.: Air parcel trajectory analysis of stable isotopes in water vapor in the eastern Mediterranean, J. Geophys. Res., 113, D20104, doi:10.1029/2008JD009839, 2008.

Pfahl, S. and Wernli, H.: Lagrangian simulations of stable isotopes in water vapor: an evaluation of nonequilibrium fractionation in the Craig-Gordon model, J. Geophys. Res., 114, D20108, doi:10.1029/2009JD012054, 2009.

Raz-Yaseef, N., Yakir, D., Schiller G., and Cohen, S.: Dynamics of evapotranspiration partitioning in a semi-arid forest as affected by temporal rainfall patterns, Agr. Forest Meteorol., 157,77-85 , 2012.

Rindsberger, M., Magaritz, M., Carmi, I., and Gilad, D.: The relation between air mass trajectories and the water isotope composition of rain in the Mediterranean Sea area, Geophys. Res. Lett., 10, 43-46, 1983.

Risi, C., Bony, S., Vimeux, F., and Jouzel, J.: Water-stable isotopes in the LMDZ4 general circulation model: model evaluation for present-day and past climates and applications to climatic interpretations of tropical isotopic records, J. Geophys. Res., 115, D12118, doi:10.1029/2009JD013255, 2010.

Risi, C., Noone, D., Frankenberg, C., and Worden, J.: Role of continental recycling in intraseasonal variations of continental moisture as deduced from model simulations and water vapor isotopic measurements, Water Resour. Res, 49, 4136-4156, doi:10.1002/wrcr.20312, 2013.

Risi, C., Landais, A., Winkler, R., and Vimeux, F.: Can we determine what controls the spatio-temporal distribution of dexcess and $17 \mathrm{O}$-excess in precipitation using the LMDZ general circulation model?, Climate of the Past, 9, 2173-2193, doi:10.5194/cp-9-2173-2013,2013b.

Robertson, J. A. and Gazis, C. A.: An oxygen isotope study of seasonal trends in soil water fluxes at two sites along a climate gradient in Washington state (USA), J. Hydrol., 328, 375-387, doi:10.1016/j.jhydrol.2005.12.031, 2006.

Salati, E., Dall'Olio, A., Matsui, E., and Gat, J.: Recycling of water in the Amazon basin : An isotopic study, Water Resour. Res, 15, 1250-1258, doi:10.1029/WR015i005p01250, 1979.

Schlosser, C. A. and Houser, P. R.: Assessing a satellite-era perspective of the global water cycle, J. Climate, 20, 1316-1338, doi:10.1175/JCLI4057.1, 2007. 
Seneviratne, S. I., Lüthi, D., Litschi, M., and Schär, C.: Landatmosphere coupling and climate change in Europe, Nature, 443, 205-209, doi:10.1038/nature05095, 2006.

Seneviratne, S. I., Corti, T., Davin, E. L., Hirschi, M., Jaeger, E. B., Lehner, I., Orlowsky, B., and Teuling, A. J.: Investigating soil moisture-climate interactions in a changing climate: a review, Earth-Sci. Rev., 99, 125-161, doi:10.1016/j.earscirev.2010.02.004, 2010.

Seneviratne, S. I., Lehner, I., Gurtz, J., Teuling, A. J., Lang, H., Moser, U., Grebner, D., Menzel, L., Schroff, K., Vitvar, T., and Zappa, M.: Swiss prealpine Rietholzbach research catchment and lysimeter: 32 year time series and 2003 drought event, Water Resour. Res., 48, W06526, doi:10.1029/2011WR011749, 2012.

Shim, J. H., Powers, H. H., Meyer, C. W., Knohl, A., Dawson, T. E., Riley, W. J., Pockman, W. T., and McDowell, N.: Hydrologic control of the oxygen isotope ratio of ecosystem respiration in a semi-arid woodland, Biogeosciences, 10, 4937-4956, doi:10.5194/bg-10-4937-2013, 2013.

Simmons, A. J., Willet, K. M., Jones, P. D., Thorne, P. W. and Dee, D. P.: Low-frequency variations in surface atmospheric humidity, temperature, and precipitation: Inferences from reanalyses and monthly gridded observational data sets, J. Geophys. Res., 115, D01110, doi:10.1029/2009JD012442, 2010.

Sodemann, H. and Zubler, E.: Seasonal and inter-annual variability of the moisture sources for Alpine precipitation during 19952002, Int. J. Climatol., 30, 947-961, doi:10.1002/joc.1932, 2010.

Sodemann, H., Schwierz, C., and Wernli, H.: Interannual variability of Greenland winter precipitation sources: lagrangian moisture diagnostic and North Atlantic Oscillation influence, J. Geophys. Res., 113, D03107, doi:10.1029/2007JD008503, 2008 a.

Sodemann, H., Masson-Delmotte, V., Schwierz, C., Vinther, B. M., and Wernli, H.: Interannual variability of Greenland winter precipitation sources: 2. Effects of North Atlantic Oscillation variability on stable isotopes in precipitation, J. Geophys. Res, 113, D12111, doi:10.1029/2007JD009416, 2008b.

Soderberg, K., Good, S. P., Wang, L., and Caylor, K.: Stable isotopes of water vapor in the vadose zone: a review of measurement and modeling techniques, Vadose Zone J., 11, doi:10.2136/vzj2011.0165, 2012.

Steppeler, J., Doms, G., Schättler, U., Bitzer, H. W., Gassmann, A., Damrath, U., and Gregoric, G.: Meso-gamma scale forecasts using the nonhydrostatic model LM, Meteor. Atmos. Phys., 82, 7596, doi:10.1007/s00703-001-0592-9, 2003.

Strong, M., Sharp, Z. D., and Gutzler, D. S.: Diagnosing moisture transport using D/H ratios of water vapor, Geophys. Res. Lett., 34, L03404, doi:10.1029/2006GL028307, 2007.

Sutanto, S. J., Wenninger, J., Coenders-Gerrits, A. M. J., and Uhlenbrook, S.: Partitioning of evaporation into transpiration, soil evaporation and interception: a comparison between isotope measurements and a HYDRUS-1D model, Hydrol. Earth Syst. Sci., 16, 2605-2616, doi:10.5194/hess-16-2605-2012, 2012.

Teuling, A. J., Seneviratne, S. I., Stöckli, R., Reichstein, M., Moors, E., Ciais, P., Luyssaert, S., van den Hurk, B., Ammann, C., Bernhofer, C., Dellwik, E., Gianelle, D., Gielen, B., Grünwald, T., Klumpp, K., Montagnani, L., Moureaux, C., Sottocornola, M., and Wohlfahrt, G.: Contrasting response of European forest and grassland energy exchange to heatwaves, Nat. Geosci., 3, 722-727, doi:10.1038/ngeo950, 2010.
Trenberth, K. E.: Atmospheric moisture residence times and cycling: implications for rainfall rates and climate change, Climatic Change, 39, 667-694, doi:10.1023/A:1005319109110, 1998.

Uemura, R., Matsui, Y., Yoshimura, K., Motoyama, H., and Yoshida, N.: Evidence of deuterium excess in water vapor as an indicator of ocean surface conditions, J. Geophys. Res., 113, D19114, doi:10.1029/2008JD010209, 2008.

Vimeux, F., Masson, V., Jouzel, J., Stievenard, M., and Petit, J. R.: Glacial-interglacial changes in oceanic surface conditions in the Southern Hemisphere, Nature, 398, 410-413, doi:10.1038/18860, 1999.

Welp, L. R., Lee, X., Griffis, T. J., Wen, X.-F., Xiao, W., Li, S., Sun, X., Hu, Z., Val Martin, M., and Huang, J.: A metaanalysis of water vapor deuterium-excess in the midlatitude atmospheric surface layer, Global Biogeochem. Cy., 26, GB3021, doi:10.1029/2011GB004246, 2012.

Wernli, H. and Davies, H. C.: A Lagrangian-based analysis of extratropical cyclones. I: the method and some applications, Q. J. Roy. Meteor. Soc., 123, 467-489, doi:10.1002/qj.49712353811, 1997.

Williams, D. G., Cable, W., Hultine, K., Hoedjes, J. C. B., Yepez, E. A., Simonneaux, V., Er-Raki, S., Boulet, G., de Bruin, H. A. R., Chehbouni, A., Hartogensis, O. K., and Timouk, F.: Evapotranspiration components determined by stable isotope, sap flow and eddy covariance techniques, Agr. Forest Meteorol., 125, 241258, doi:10.1016/j.agrformet.2004.04.008, 2004.

Yakir, D. and Sternberg, L.: The use of stable isotopes to study ecosystem gas exchange, Oecologia, 123, 297-311, doi:10.1007/s004420051016, 2000.

Yepez, E. A., Huxman, T. E., Ignace, D. D., English, N. B., Weltzin, J. F., Castellanos, A. E., and Williams, D. G.: Dynamics of transpiration and evaporation following a moisture pulse in semiarid grassland: a chamber-based isotope method for partitioning flux components, Agr. Forest Meteorol., 132, 359-376 doi:10.1016/j.agrformet.2005.09.006, 2005.

Yepez, E. A., Williams, D. G., Scott, R. L., and Lin, G.: Partitioning overstory and understory evapotranspiration in a semiarid savanna woodland from the isotopic composition of water vapor, Agr. Forest Meteorol., 119, 53-68, doi:10.1016/S01681923(03)00116-3, 2003.

Yoshimura, K., Kanamitsu, M., Noone, D., and Oki, T.: Historical isotope simulation using reanalysis atmospheric data, J. Geophys. Res., 113, D19108, doi:10.1029/2008JD010074, 2008.

$\mathrm{Yu}, \mathrm{L}$. and Weller, R. A.: Objectively analyzed air-sea heat fluxes for the global ice-free oceans, B. Am. Meteorol. Soc., 88, 527539, doi:10.1175/BAMS-88-4-527, 2007.

Zhang, S., Wen, X., Wang, J., Yu, G., and Sun, X.: The use of stable isotopes to partition evapotranspiration fluxes into evaporation and transpiration, Acta Ecologica Sinica, 30, 201-209, doi:10.1016/j.chnaes.2010.06.003, 2010. 
Table A1. Isotopic composition of $\sim 10$ days accumulated soil moisture samples from the lysimeter collected at the measurement station Rietholzbach between 27 July 2011 and 12 January 2012.

\begin{tabular}{lccc}
\hline Date & $\delta^{18} \mathrm{O}[\% \circ]$ & $\delta^{2} \mathrm{H}[\% \circ]$ & $d[\% \circ]$ \\
\hline 27 Jul-12 Aug & $-10.76 \pm 0.14$ & $-73.91 \pm 0.51$ & $12.19 \pm 1.63$ \\
12 Aug-25 Aug & $-11.00 \pm 0.09$ & $-75.48 \pm 0.44$ & $12.51 \pm 1.14$ \\
25 Aug-06 Sep & $-11.10 \pm 0.12$ & $-76.97 \pm 0.69$ & $11.80 \pm 1.62$ \\
06 Sep-21 Sep & $-11.09 \pm 0.07$ & $-78.50 \pm 0.44$ & $10.23 \pm 0.97$ \\
21 Sep-05 Oct & $-11.21 \pm 0.06$ & $-78.65 \pm 0.22$ & $11.05 \pm 0.69$ \\
05 Oct-18 Oct & $-11.47 \pm 0.08$ & $-80.51 \pm 0.56$ & $11.26 \pm 1.16$ \\
18 Oct-01 Nov & $-11.32 \pm 0.06$ & $-80.22 \pm 0.11$ & $10.36 \pm 0.55$ \\
01 Nov-18 Nov & $-11.26 \pm 0.06$ & $-79.35 \pm 0.50$ & $10.70 \pm 0.98$ \\
18 Nov-28 Nov & $-11.18 \pm 0.09$ & $-79.20 \pm 0.65$ & $10.21 \pm 1.39$ \\
28 Nov-13 Dec & $-11.20 \pm 0.06$ & $-81.74 \pm 0.56$ & $7.85 \pm 1.07$ \\
13 Dec-26 Dec & $-10.49 \pm 0.36$ & $-74.56 \pm 0.38$ & $9.33 \pm 3.26$ \\
26 Dec-12 Jan & $-10.13 \pm 0.09$ & $-68.42 \pm 0.34$ & $12.65 \pm 1.04$ \\
\hline
\end{tabular}

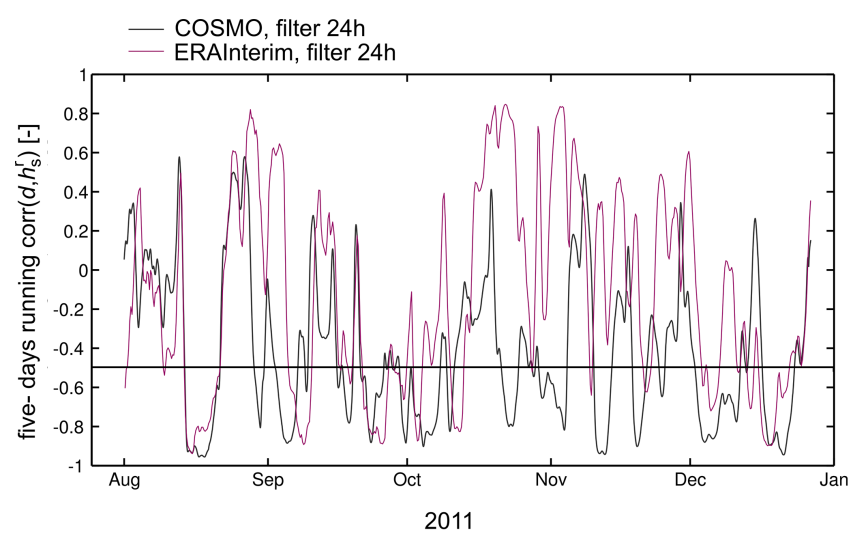

Fig. A1. Comparison of the 5-day moving window correlation between $24 \mathrm{~h}$ filtered $d$ and diagnosed source $h_{\mathrm{s}}^{\mathrm{r}}$ with COSMO (grey) and with ERA-Interim (violet). The horizontal black line shows the $\operatorname{corr}\left(d, h_{\mathrm{s}}^{\mathrm{r}}\right)=-0.5$ line used as a threshold for the HRA event definition in Sect. 5.3.

\section{Appendix A}

\section{The closure assumption and $d$ of the moisture source}

According to the closure assumption of Merlivat and Jouzel (1979) the only source of vapour in the boundary layer is surface evaporation. The isotopic ratio of the evaporation flux $R_{\mathrm{e}}$ in this case equals the isotopic ratio of boundary layer vapour $R_{\mathrm{V}}$ :

$R_{\mathrm{e}}=R_{\mathrm{v}}$.

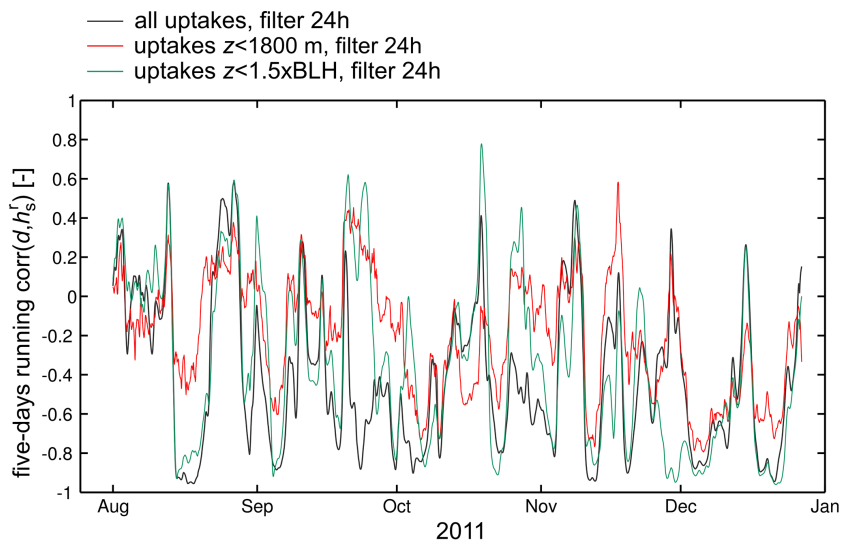

Fig. A2. Sensitivity of the 5-day moving window correlation between $d$ and $h_{\mathrm{s}}^{\mathrm{r}}$ to the uptake height threshold. A comparison is shown of the correlation pattern with a fixed uptake threshold altitude of $1800 \mathrm{~m}$ (green curve), with an uptake threshold altitude of 1.5 times the boundary layer height (red curve) and without an uptake height threshold (grey curve).

The isotope ratio of the evaporation flux following Craig and Gordon (1965) is

$R_{\mathrm{e}}=\frac{\frac{R_{\mathrm{l}}}{\alpha}-h_{\mathrm{s}} \cdot R_{\mathrm{v}}}{\alpha^{\mathrm{k}}\left(1-h_{\mathrm{s}}\right)}$,

where $\alpha$ is the equilibrium fractionation factor, $\alpha^{\mathrm{k}}$ the nonequilibrium fractionation factor, $R_{1}$ the isotope ratio of the liquid water and $h_{\mathrm{s}}$ the relative humidity with respect to the surface temperature.

If the closure assumption (Eq. (A1)) is applied, Eq. (A2) simplifies to

$R_{\mathrm{v}}=\frac{R_{1}}{\alpha\left(\alpha^{\mathrm{k}}+h_{\mathrm{s}}\left(1-\alpha^{\mathrm{k}}\right)\right)}$.

For $h_{\mathrm{s}}=1$ we have

$R_{\mathrm{v}}=\frac{R_{1}}{\alpha}$.

The $d$ is derived from $R_{\mathrm{v}}^{18} \mathrm{O}$ and $R_{\mathrm{v}}^{2} \mathrm{H}$ and is not substantially affected by equilibrium fractionation, thus $d_{\mathrm{s}}^{r}\left(h_{\mathrm{s}}^{\mathrm{r}}=100 \%\right)$ provides information on the average $d$ of liquid water at the moisture source. 


\section{Appendix B}

\section{Derivation of Eq. (3) for the estimation of the transpira- tion fraction of continental evaporation}

When assuming closure for total evaporation, the heavy isotope ratio of the water vapour mix $R_{\mathrm{V}}$ containing moisture originating from ocean evaporation $R_{\mathrm{vo}}$, plant transpiration $R_{\mathrm{vt}}$ and soil evaporation $R_{\mathrm{ve}}$ is

$R_{\mathrm{v}}=f_{\mathrm{o}} R_{\mathrm{vo}}+\left(1-f_{\mathrm{o}}\right) \cdot\left[f_{\mathrm{t}} \cdot R_{\mathrm{vt}}+\left(1-f_{\mathrm{t}}\right) \cdot R_{\mathrm{ve}}\right]$.

If we replace $R_{\mathrm{vo}}$ and $R_{\mathrm{ve}}$ by their respective expression using the Craig and Gordon (1965) model (Eq. A2) and assuming that $R_{\mathrm{vt}}=R_{\mathrm{c}}$ with $R_{\mathrm{c}}$ the isotope ratio of liquid soil water we obtain

$$
\begin{aligned}
R_{\mathrm{v}}=f_{\mathrm{o}} \frac{R_{\mathrm{o}} \frac{1}{\alpha}-h_{\mathrm{s}} R_{\mathrm{v}}}{\alpha_{\mathrm{o}}^{\mathrm{k}}\left(1-h_{\mathrm{s}}\right)}+\left(1-f_{\mathrm{o}}\right) \\
\cdot\left[f_{\mathrm{t}} \cdot R_{\mathrm{c}}+\left(1-f_{\mathrm{t}}\right) \frac{R_{\mathrm{c}} \frac{1}{\alpha}-h_{\mathrm{s}} R_{\mathrm{v}}}{\alpha_{\mathrm{c}}^{\mathrm{k}}\left(1-h_{\mathrm{s}}\right)}\right] \\
\Rightarrow R_{\mathrm{V}}\left[1+f_{\mathrm{o}} \frac{h_{\mathrm{s}}}{\alpha_{\mathrm{o}}^{\mathrm{k}}\left(1-h_{\mathrm{s}}\right)}+\left(1-f_{\mathrm{o}}\right)\left(1-f_{\mathrm{t}}\right) \frac{h_{\mathrm{s}}}{\alpha_{\mathrm{c}}^{\mathrm{k}}\left(1-h_{\mathrm{s}}\right)}\right] \\
=f_{\mathrm{o}} \frac{R_{\mathrm{o}} \frac{1}{\alpha}}{\alpha_{\mathrm{o}}^{\mathrm{k}}\left(1-h_{\mathrm{s}}\right)}+\left(1-f_{\mathrm{o}}\right)\left[f_{\mathrm{t}} R_{\mathrm{c}}+\left(1-f_{\mathrm{t}}\right) \frac{R_{\mathrm{c}} \frac{1}{\alpha}}{\alpha_{\mathrm{c}}^{\mathrm{k}}\left(1-h_{\mathrm{s}}\right)}\right]
\end{aligned}
$$

Dividing through the brackets on the left-hand side yields Eq. (3).

\section{Appendix C}

Sensitivity of transpiration fraction estimate on closure assumption and non-equilibrium fractionation factor

The closure assumption can be applied to Eq. (B1) in three different ways:

1. Overall, for the total evaporation flux, to obtain Eq. (3).

2. For continental and oceanic sources separately to obtain

$$
\begin{aligned}
R_{\mathrm{v}} & =f_{\mathrm{o}} \frac{R_{\mathrm{o}}}{\alpha\left(\alpha_{\mathrm{o}}^{\mathrm{k}}+h_{\mathrm{s}}\left(1-\alpha_{\mathrm{o}}^{\mathrm{k}}\right)\right)} \\
& +\left(1-f_{\mathrm{o}}\right)\left[f_{\mathrm{t}} \frac{R_{\mathrm{c}}\left(1-h_{\mathrm{s}}\right)}{1-h_{\mathrm{s}}\left(1-\frac{1}{\alpha_{\mathrm{c}}^{\mathrm{k}}}\left(1-f_{\mathrm{t}}\right)\right)}\right. \\
& \left.+\left(1-f_{\mathrm{t}}\right) \frac{R_{\mathrm{c}}}{\alpha \alpha_{\mathrm{c}}^{\mathrm{k}}\left(1-h_{\mathrm{s}}\left(1-\frac{1}{\alpha_{\mathrm{c}}^{\mathrm{k}}}\left(1-f_{\mathrm{t}}\right)\right)\right)}\right] .
\end{aligned}
$$

3. For each individual evaporation type, i.e. ocean evaporation, soil evaporation and plant transpiration separately, to obtain

$$
\begin{aligned}
& R_{\mathrm{v}}=f_{\mathrm{o}} \frac{R_{\mathrm{o}}}{\alpha\left(\alpha_{\mathrm{o}}^{\mathrm{k}}+h_{\mathrm{s}}\left(1-\alpha_{\mathrm{o}}^{\mathrm{k}}\right)\right)} \\
& +\left(1-f_{\mathrm{o}}\right)\left[f_{\mathrm{t}} R_{\mathrm{c}}+\left(1-f_{\mathrm{t}}\right) \frac{R_{\mathrm{c}}}{\alpha\left(\alpha_{\mathrm{c}}^{\mathrm{k}}+h_{\mathrm{s}}\left(1-\alpha_{\mathrm{c}}^{\mathrm{k}}\right)\right)}\right] .
\end{aligned}
$$

The transpiration fractions for HRA and HLA events obtained from these three approaches differ by a maximum of $2 \%$ and $6 \%$ respectively. When using version 1 the average $f_{\mathrm{t}}$ is $62 \%$ for HRA events and $76 \%$ for HLA events; when using version 2 the average $f_{\mathrm{t}}$ is $61 \%$ for HRA events and $78 \%$ for HLA events; when using version 3 the average $f_{\mathrm{t}}$ is $63 \%$ for HRA events and $82 \%$ for HLA events.

When using the closure version 1 and the non-equilibrium fractionation factors for wet (dry) soils from Mathieu and Bariac (1996), the transpiration fraction range for HRA events is $0-89 \%(31-92 \%)$ and for HLA events 65$86 \%(73-89 \%)$. Particularly for low transpiration fractions, when soil evaporation is important, the choice of the nonequilibrium fractionation factor becomes very important. 


\section{Appendix D}

\section{Sensitivity of anticorrelation modes to uptake diagnostic parameters}

\section{D1 Global reanalysis compared to regional model analysis data for trajectory calculation}

The impact of using ERA-Interim data instead of COSMO data as a basis for the trajectory calculation and the moisture source identification on the correlation structure between $d$ and diagnosed source $h_{\mathrm{s}}^{\mathrm{r}}$ is large only for a few events (Fig. A1), for example, in mid-November. Many HRA events discussed in Sect. 5.3 are also found using ERA-Interim data (67\%, 14 HRA events of 21). Sometimes a small temporal shift of the start and end of the HRA events or the strength in the anticorrelation can be noticed. Five supplementary HRA events are found with ERA-Interim that are not present in the $d-h_{\mathrm{s}}^{\mathrm{r}}$ running window correlation using COSMO. These ERA-Interim HRA events are strongly influenced by sources outside the COSMO domain and the fraction of explained moisture is below $50 \%$ using the COSMO trajectories. The seven HRA events found using COSMO but not detected using the $d-h_{\mathrm{s}}^{\mathrm{r}}$ running window correlation from ERA-Interim are not identified either when using 6-hourly changes in specific humidity along the COSMO trajectory data for the moisture source identification. These events can thus only be detected with higher temporal resolution of the evolution of specific humidity along the trajectories. Due to the limited model domain, the moisture sources identified with COSMO trajectories strongly emphasise continental sources. The modes of anticorrelation between $d$ and $h_{\mathrm{s}}^{\mathrm{r}}$ found using COSMO trajectories thus reflect large-scale situations with a strong continental recycling component.

\section{D2 Impact of setting an uptake height threshold}

The uptake height has been mentioned in Sect. 3.2 as an important parameter in the setup of the moisture source diagnostic. To distinguish between cloud processes and surface evaporation an uptake height threshold can be set above which the uptakes along the trajectories are not considered. However, convection can be associated with strong moist updrafts, which can lead to a rapid vertical mixing over a layer deeper than the boundary layer. Although, based upon detailed analysis of a few cases, we regard the diagnosed aboveboundary layer uptakes as relevant (Aemisegger, 2013), we assess here the impact of the boundary layer height threshold on the temporal correlation pattern between $d$ and $h_{\mathrm{s}}^{\mathrm{r}}$ at the moisture source. In Fig. A2 the 5-day moving window correlation is shown between $24 \mathrm{~h}$ filtered $d$ and source $h_{\mathrm{s}}^{\mathrm{r}}$ using all uptakes (grey line in Fig. A2) and only uptakes occurring below a fixed maximum uptake height of $1800 \mathrm{~m}$ (red line in Fig. A2). The differences between the two moving window correlation signals are small in November and December, but larger in the warm season, in which parameterised convection plays an important role. In this study, choosing a maximum uptake height that is $50 \%$ higher than the model boundary layer height as in previous studies (Sodemann et al., 2008a; Pfahl and Wernli, 2008) does not impact the moving correlation signal significantly (compare the grey and green curves in Fig. A2). With the scaled boundary layer top as a maximum uptake height we miss a few HRA events (e.g. one at the end of September, one at the beginning of October and one at the end of October). Furthermore, the anticorrelation found here is generally weaker when using the scaled boundary layer height as an uptake threshold than without uptake threshold, especially in summer. This confirms that the approach of considering all uptakes leads to meaningful results here but obviously does not preclude the use of the boundary layer height criterion for other studies. 